\title{
PUBLIC HEALTH POLICY AT SCALE: IMPACT OF A GOVERNMENT-SPONSORED INFORMATION CAMPAIGN ON INFANT MORTALITY IN DENMARK
}

\author{
Onur Altindag \\ Jane Greve \\ Erdal Tekin \\ Working Paper 28621 \\ http://www.nber.org/papers/w28621 \\ NATIONAL BUREAU OF ECONOMIC RESEARCH \\ 1050 Massachusetts Avenue \\ Cambridge, MA 02138 \\ March 2021, Revised March 2022
}

We gratefully acknowledge financial support from Novo Nordisk Foundation (Grant: NNF180C0034296). We thank Dhaval Dave, Daniel Dench, Else Guldager, Lars Iversen, Theodore Joyce, Stephen D. O'Connell, Daniel Rees, Hannes Schwandt, Kiersten Strombotne, and seminar participants at Bentley University, Erasmus School of Economics, and VIVE for comments and suggestions. The views expressed herein are those of the authors and do not necessarily reflect the views of the National Bureau of Economic Research.

NBER working papers are circulated for discussion and comment purposes. They have not been peer-reviewed or been subject to the review by the NBER Board of Directors that accompanies official NBER publications.

(C) 2021 by Onur Altindag, Jane Greve, and Erdal Tekin. All rights reserved. Short sections of text, not to exceed two paragraphs, may be quoted without explicit permission provided that full credit, including $\odot$ notice, is given to the source. 
Public Health Policy at Scale: Impact of a Government-sponsored Information Campaign on Infant Mortality in Denmark

Onur Altindag, Jane Greve, and Erdal Tekin

NBER Working Paper No. 28621

March 2021, Revised March 2022

JEL No. I12,I18,I24

\title{
ABSTRACT
}

We evaluate the impact of a nationwide public health intervention on deaths from sudden infant death syndrome (SIDS), using population data from Denmark in a regression discontinuity research design. The information campaign-implemented primarily through a universal nurse home visiting program-reduced infant mortality by 17.2 percent and saved between 11.6-13.5 lives over 10,000 births. The estimated effect sizes are 11-14 times larger among low birthweight and preterm infants relative to the overall population. Improvement in infant mortality is concentrated among those with low socio-economic status and with limited access to health information, thereby reducing health inequities at birth.

\author{
Onur Altindag \\ Bentley University \\ 175 Forest $\mathrm{St}$ \\ Waltham, Mass 02452-4713 \\ United States \\ oaltindag@bentley.edu \\ Jane Greve \\ VIVE - The Danish Center for \\ Social Science Research \\ Herluf Trolles Gade 11 \\ 1052 Copenhagen \\ Denmark \\ jagr@vive.dk
}

\author{
Erdal Tekin \\ School of Public Affairs \\ American University \\ 4400 Massachusetts Avenue NW \\ Washington, DC 20016-8070 \\ and IZA \\ and also NBER \\ tekin@american.edu
}




\section{Introduction}

Medical innovations and public health achievements pioneered during the $20^{\text {th }}$ century led to an increase in life expectancy from 32 to over 66 years, an improvement unprecedented in human history. ${ }^{1}$ Decline in infant mortality accounts for the largest share in explaining the rise in longevity, brought about by filtering and chlorinating water supplies, sanitation systems, mass vaccination, sulfanilamides and antibiotics, improvements in food safety and nutrition, greater access to health services, and advances in medical technology (Alsan and Goldin 2019; Anderson et al. 2020b, 2021; Cutler et al. 2006; Cutler and Miller 2005; Horton and Steckel 2013; Meckel 1998; Miller and Goldman 2011; Ward and Warren 2006). Another contributor to the decline in infant mortality has been the transmission of knowledge gained from scientific advancements and health innovations to mass populations, which usually requires well-coordinated, large-scale public education campaigns. ${ }^{2}$ In fact, scientific advancements and health innovations would have a limited chance of success if the knowledge gained from these developments are not communicated to the public in a way that results in the adoption of behaviors promoting infant health. Therefore, it is critical to understand the relative importance of efforts focused on information provision as a policy instrument.

Acknowledging the crucial role of medical knowledge in obstetrics and pediatrics in reducing preventable deaths among infants, developed countries established public health communication strategies to diffuse practical information to new parents. In this study, we investigate the impact of government-directed and sponsored efforts to communicate newly emerged medical knowledge on infant mortality in Denmark. In 1991, the Danish government issued a new set of guidelines regarding risk factors for sudden infant death syndrome (SIDS), recommending that infants sleep either on their back or side, which went against the then-existing recommendation that had encouraged sleeping on the stomach (Guldager et al. 1990). To communicate the new guidelines to new parents and lower the prevalence of risk factors for SIDS, the government launched a nationwide information campaign in December 1991. ${ }^{3}$ While information on the new guidelines was also disseminated through the media outlets and health professionals (mainly at maternity wards), an evaluation from 1993 shows that 62 percent of the parents rate the home visiting nurses as the most important source of information with regards to the guideline on sleeping position (Møller et al. 1994). Established in 1937, the home nurse visiting program involves multiple home visits throughout the first year of life, with more regular visits in the first several weeks after birth. The program is universally available to all Danish families with a near 100-percent take-up rate (Hjort et al. 2017). Postnatal home visits by public health nurses administered under the program provided an ideal tool to communicate the updated guidelines due to its capacity to reach all new parents and build a trust-based relationship through repeated visits of the same nurse.

\footnotetext{
${ }^{1}$ https:/ / ourworldindata.org/life-expectancy.

2See Deaton (2006); Cutler et al. (2006) for a summary of historical determinants of mortality.

${ }^{3}$ See Appendix A for a copy of the letter from the National Board of Health to all GPs, maternity wards, hospitals, midwifes, and home visiting nurses in December 1991.
} 
We use a regression discontinuity design that involves comparing all-cause and cause-specific mortality risk for births occurred just before and after the unanticipated change in government recommendation and the subsequent public information campaign to change parental practices concerning the sleep position of their newborns. Although exact causes are unknown, the majority of SIDS deaths occur before the age of 4 months, which provides an opportunity to observe the immediate impact of changing sleeping environment on infant health (American Academy of Pediatrics 2011). We show that the nationwide information campaign was highly effective in reducing infant mortality, especially among infants with poor baseline health and lower socioeconomic status. Our estimates suggest that the campaign reduced infant mortality rate by 17.2 percent, which can explain around one quarter of the overall decrease in infant mortality over the past 40 years in Denmark. Decrease in deaths from SIDS and unknown causes fully account for the overall drop in infant mortality. We estimate that the intervention reduced infant mortality for low birthweight and preterm children by 1.5 and 1.9 percentage points, which is 11 and 14 times larger than its impact on the overall population, respectively. Furthermore, the intervention was most effective in improving the health of infants from immigrant or lower educated mothers. These results underscore the effective role that an information-based, universally-accessible public health intervention can play in narrowing early life health disparities.

Our analysis contributes to two strands of literature. First is the literature investigating the impact of public education campaigns on health behaviors. These investigations focus on the role of information diffusion on influencing the public opinion and health behaviors, such as immunization, breastfeeding, dietary habits, smoking and alcohol consumption, etc. (Weiss and Tschirhart 1994; de Walque 2007; Olds et al. 2007; de Walque 2010; Dupas 2011). However, most of the existing evidence come from contexts in which the campaigns are limited in scope or targeted at specific groups. Second, we contribute to the literature investigating the interplay among public health interventions, mortality transition, and health inequalities in high income countries (Cutler and Miller 2005; Cutler et al. 2006; Watson 2006; Wüst 2012; Moehling and Thomasson 2014; Komisarow 2017; Alsan and Goldin 2019; Anderson et al. 2019; Feigenbaum et al. 2019; Anderson et al. 2020a).

While prior literature documents the declines in SIDS deaths through public health policy campaigns with varying success in Scandinavia and other high income countries, these analyses are typically based on crude trend evaluations and case control studies relying on small samples (Wennergren et al. 1997; Hauck and Tanabe 2008; MacDorman et al. 2013; Goldstein et al. 2016). In contrast, our analysis isolates the impact of a universal public health education campaign within a narrow time frame, and using outcomes that are not prone to diagnostic challenges in classifying SIDS (Hauck and O Tanabe 2010; Hauck and Tanabe 2008). Furthermore, we leverage population-level data to precisely estimate the impact of the intervention on vulnerable subpopulations, which shows evidence of substantial benefits in targeting those with poor baseline health, lower socioeconomic status, and thus limited access to useful medical information. Countries 
with constrained resources or unequal access to health knowledge might benefit from this type of targeted interventions to reduce infant mortality among susceptible populations and improve early life health disparities. Our findings are particularly relevant for the United States, that currently has a higher infant mortality rate than European countries driven by higher postneonatal mortality (1-12 months after birth), a period in which SIDS is still the leading cause of death (Carlin and Moon 2017; Chen et al. 2016).

\section{Infant Mortality and SIDS in Denmark}

Infant mortality in Denmark decreased from 134.2 over 1000 live births in 1901 to 20 in 1962, and eventually to only 3.2 in 2019. ${ }^{4}$ Until the 1950s, unexplained deaths constituted a small fraction of the overall infant mortality, but as deaths due to infections and other major causes continuously declined over the second half of the century, unexplained infant deaths slowly shifted from the periphery to the center of public health policy (Helweg-Larsen and Guldager 2001b). Formally defined as a cause of death in 1969, reported SIDS rates steadily increased over the next 20 years in many developed countries, including Denmark, eventually making SIDS the most significant post-neonatal risk for infant mortality in industrialized countries (De Jonge et al. 1989; Dwyer and Ponsonby 2009). Research in Denmark suggests that the changes in cause of death classifications and the previous guidelines that recommended sleeping on stomach might explain the rise of SIDS deaths (Helweg-Larsen et al. 1992).

While the association between prone sleeping position and SIDS was known as early as the 1970s, the full recognition by the medical community and the subsequent policy action did not occur until early 1990s, after multiple case control, cohort, and observational studies from the UK, Netherlands, Australia, and New Zealand (De Jonge et al. 1989; Dwyer et al. 1991; Fleming et al. 1990; Mitchell et al. 1991). This prompted a series of information campaigns across developed countries, stressing prone sleep position as a high risk factor for SIDS and thus recommending supine sleeping. In Denmark, the recognition of this new scientific information occurred in December 1991 when the National Board of Health, in a reversal of its previous position, issued revised guidelines, recommending that infants sleep either on their back or side. Concomitantly, the government launched a public education campaign, with a key role assigned to the home visiting nurse program in transmitting the information in the new guidelines to parents. ${ }^{5}$ The news on the campaign was also circulated in the media, initiated through a press release from the National Board of Health (Guldager 1992; Helweg-Larsen and Guldager 2001a). ${ }^{6}$ Specifically, the National

${ }^{4}$ Estimates between 1901 to 1962 come from Matthiessen (1967) and 2019 from World Bank Open Data (https: //data. worldbank. org/indicator/SP. DYN. IMRT . IN?locations=DK.

${ }^{5}$ Appendix B provides a detailed description of the Danish home visiting program.

${ }^{6}$ However, the media coverage of the information campaign appears limited. A search of the newspaper archives of the Danish nationwide media identified 15 SIDS-related articles in 1991, only two of which were related to the new guidelines. There were ten SIDS-related articles in 1992, only one of which mentioned sleep position as an important factor for SIDS. 
Board of Health published a special issue in the Public Health Nurses trade magazine in early 1992, which translated the new evidence on preventive measures related to SIDS and the content of the new guidelines. ${ }^{7}$ It also included a description of the public health nurses' role in the implementation of the guideline related to sleeping position. The special issue was delivered to all public health and obstetric nurses along with a pamphlet including a list of recommendations regarding the importance of sleeping on the back as well as avoidance of smoking and overheating. ${ }^{8}$

While we do not have data to assess the impact of the campaign on parental practices concerning the sleep position of their babies, the Danish National Board of Health evaluated the information campaign in five regions in Denmark in 1993 and determined that the vast majority of parents complied with the new guidelines. A survey conducted by the evaluation team indicated that while almost all parents had been aware of the importance of supine sleeping position, only about half of the parents had been informed about the guidelines on smoking and overheating. By 1993, approximately 13 percent of infants of parents with more than one child were sleeping on their stomach, corresponding to a 38.2 percentage points decrease from the pre-1991 levels (Møller et al. 1994).

The risk of SIDS differs by several factors. For example, premature birth and higher order births are associated with an increased risk of SIDS. Before the campaign, the prematurely born babies were often laid on their stomach for sleep in the hospitals based on the belief that doing so helped them with breathing and sleeping more comfortably (Helweg-Larsen and Guldager 2001c). Most parents maintained this practice upon returning home with their newborns. Parents with older children were also more likely to put their children to sleep on their stomach following the previous guidelines as changing an existing health behavior without the right incentives is often challenging (Loewenstein et al. 2016; Hussam et al. 2017). This may be particularly salient in our setting, where parental compliance could be more difficult to achieve given that sleeping on their stomach was viewed as more comfortable for many infants as they woke up less frequently at night. (Horne et al. 2001; Oster 2020, pp. 111-112). Additionally, children from certain backgrounds are particularly vulnerable to SIDS. For example, an evaluation of immigrants' infant care in Denmark from 1994 shows that immigrant parents were much more likely to practice prone sleep position with their babies than were Danish parents (Sonne 1994).

\section{Data}

We use several Danish population registries that are linked through a unique identifier to construct a data set of all live births from 1973 through 2006. Information on birth weight, gestational age, and parity are obtained from the Danish Medical Birth Registry (DMBR). ${ }^{9}$ Maternal age and

\footnotetext{
${ }^{7}$ In Danish: Fagtidsskriftet Sundhedsplejersken.

${ }^{8}$ This material included the pamphlet aimed at the parents and two publications "Barn i vente" (in English: Expecting a child) and "Sunde børn" (in English: "Healthy Children").

${ }^{9}$ We exclude observations with no information or unrealistic values for birthweight and height.
} 
immigrant status are also obtained from DMBR. Mortality data including the exact date and cause of death come from the Danish Registry of Cause of Death (Helweg-Larsen 2011). ${ }^{10}$ Information on parental education comes from the Danish Education Registry. We categorize mothers to those with (i) basic education (12 years or less of formal education), (ii) vocational education (vocational training equivalent to high school), and (iii) further education (women with any post-high school degree). We provide a detailed description of the variables used in the analysis in Appendix Table C1. Appendix Table C2 presents the descriptive statistics for the analysis variables .

\section{Empirical Design}

Our empirical strategy anchors on the notion that children who were born after December 1991 were exposed to an at-scale information campaign that aimed to reverse the sleep practice of newborns in Denmark. In particular, we use a regression continuity design based on the birth date of the newborn using the cutoff date of December 31, 1991, which creates a quasi-random variation in exposure to the drastically different sleep guidelines provided by the government. ${ }^{11}$

Formally, our research design can be expressed by the following empirical specification:

$$
\begin{gathered}
y_{i}=\alpha+\tau d_{i}+f\left(s_{i}\right)+\epsilon_{i} \\
\forall s_{i} \in(c-h, c+h)
\end{gathered}
$$

where $y_{i}$ indicates mortality outcome for infant $i, d_{i}$ is a binary treatment indicator for cohorts born in January 1992 and later, and $s_{i}$ is the running variable and calculated as the number of days between the child's birthdate and the end of December 1991. We fit two continuous functions $f\left(s_{i}\right)$ on each side of the regression sample, which includes infants who were born $h$ days before and after the change in guidelines, using an automated routine of optimal bandwidth selection that minimizes the mean-squared error (MSE) following Calonico et al. (2019). We also present results from a wide range of alternative bandwidths to test the sensitivity of our estimates with respect the bandwidth choice. Standard errors are clustered at the birthday level to account for within birthday correlations in outcomes. Finally, we use a uniform kernel to weight the observations in our regression sample.

In this setting, $\tau$ captures the intent-to-treat (ITT) effect of a change in sleep position achieved through a nationwide public information campaign. Causal interpretation of this parameter further hinges on the following assumptions: (i) quasi-random assignment, i.e., cohorts who were born just before and after the change in guidelines are exposed to different sleep environments but are otherwise comparable in their pre-treatment characteristics; and (ii) exclusion restriction, i.e., there are no other policies that were implemented around the same time and could also generate similar

${ }^{10}$ Unique identifiers in the registries link parents and children.

${ }^{11}$ We obtain remarkably similar results in all specifications including the robustness tests when we use the birth month and year as our running variable instead of the exact birthday. 
discontinuous mortality risk across birth cohorts born around the cutoff date. We take advantage of the population-level administrative data to assess the validity of these assumptions. First, we analyze whether a set of predetermined covariates including strong predictors of infant mortality are continuous around the threshold to confirm quasi-random assignment of exposure to policy. Second, we use cause-specific mortality data to confirm that any sharp drop in infant mortality is exclusively driven by SIDS and other unclassified deaths and test whether excluding those leads to a null treatment effect. This provides a powerful empirical test on exclusion restriction, given the statistical power provided by the population-level data, as well as the existing medical evidence that having infants sleep on their back is the most important risk-reducing practice against SIDS (Dwyer and Ponsonby 2009).

\section{Results}

\subsection{Descriptive Analysis and Preliminary Tests}

We begin with a descriptive analysis of our main outcomes in Figure 1, i.e., the all-cause infant mortality and SIDS rates over 10,000 live births for infants born between 1973 and 2006. With the exception of 1980s, infant mortality rate continuously fell throughout the analysis period. The drop in the rate is particularly dramatic in early 1990s during which it plummeted from around 80 per 10,000 in its 1980 levels to 50 per 10,000, corresponding to a 35-40 percent decline within only four birth cohorts between 1991 and 1994.

Figure 1 Panel B shows that (i) the decline in infant mortality during the early 1990s shown in Figure 1, Panel A, is primarily driven by an abrupt decrease in SIDS deaths, and (ii) for infants born between the early 1970s and 1990, the SIDS rate gradually increased despite a drop in overall infant mortality. For the most part, this increase is attributable to improved classification of cause of death, though epidemiological literature also points to the previous clinical guidelines that advised the parents to put their babies to sleep on their stomach during 1980s (Helweg-Larsen and Guldager 2001b). A trend analysis suggests that birth cohorts born after the new guidelines were introduced in 1991 experienced a 3 to 4-fold decrease in SIDS-related mortality risk. For cohorts born in the 2000s this mortality risk remained stable and near zero. Due to confounding secular trends in infant mortality and the time-varying measurement error in SIDS classification, however, it is difficult to quantify the true effect of a policy on infant mortality through a trend analysis without additional strong assumptions.

To assess the internal validity of our research design, we first test whether cohorts born right before and right after introduction of new guidelines differ in their observed characteristics. In Table 1, we report the RD estimates using Equation 1, which reflects the differences in observed predetermined characteristics of the treatment and control groups for a wide range of bandwidths. The first column shows results of the continuity tests for the optimal bandwidth obtained using the Calonico et al. (2019) routine. The estimates in the remaining columns are obtained from samples 
restricted from 1000 to 2000 days below and above the index threshold.

The results in Table 1 support the assumption of quasi-random assignment of the treatment status around the vicinity of the RD threshold after accounting for the secular linear trends on either side of it. The residual differences between the treatment and control groups are small in magnitude and most of them are not statistically significant, despite huge sample sizes. The only consistent difference that we can detect is on birth order coefficients, which suggest that the treatment group's birth order is 0.016 higher, on average, than the control group, which has a mean birth order of 1.74 (Table 1, column 1). While the sign of the coefficient suggests a negative selection into treatment, its size is not clinically meaningful enough to have any impact on infant mortality. ${ }^{12}$

In Appendix Figure B1, we report the graphical representation of these estimates generated using the monthly birth cohorts and corresponding optimal-bandwidth. As revealed by the figure, the treatment assignment does not show any meaningful jumps around the policy threshold. The visual inspection also confirms the findings in Table 1, showing that birth cohorts who were born around the drastic policy change have very similar baseline health and maternal characteristics. Given that some of these covariates are strong predictors of infant mortality, the balance of these covariates across birth cohorts supports the internal validity of our research design.

Note that because we use population-level administrative data, there is no measurement error in our running variable that could result from self-reported date of birth. Given the cohortbased structure, it is also unlikely that some parents might have manipulated the timing of their childbearing in our context. Therefore, endogenous selection to analysis sample or bunching near the cut-off do not constitute threats to the validity of our research design. These arguments are also supported by Figure B2, which shows no change in population composition around the threshold that could explain the dramatic drop in mortality.

\subsection{RD Estimates on All-cause and SIDS-specific Mortality}

Figure 2 shows the RD graphs from an analysis sample restricted by Calonico et al. (2019)'s MSEoptimal bandwidth for our main outcomes. In panel (a), the SIDS mortality rate exhibits a clear break towards zero immediately following the change in guidelines. Panel (b) includes deaths from SIDS and unclassified causes, and here a similar break is observed. We quantify these breaks in the first column of Table 2, which indicates a decrease of 11.7 SIDS deaths per 10,000 live births from a control group mean of 17.7 SIDS deaths per 10,000 live births. Effect sizes are robust to various sample restrictions and range between 9.9 and 11.7 based on the distance in days to the index date, which varies between 1000 and 2000.

All-cause infant mortality in panel (c) of Figure 2 also shows a clear break in infant mortality immediately after the change in recommended sleep position. The coefficient size indicates that 13.2 deaths per 10,000 live births were averted due to change in public health guidelines, which is slightly more than the estimates for the SIDS-specific mortality rate (Table 2, column 1). The point

\footnotetext{
${ }^{12}$ As expected, controlling for these variables makes no difference to our reported results. See Appendix Table C3.
} 
estimates are remarkably robust to bandwidth selection and vary between 11.6 and 13.5, despite the dramatic change in sample sizes. The relative effect sizes are large and indicate a 17.2 percent decrease in infant mortality compared to the control mean of 76.82 deaths per 10,000 live births. In Figure 2, we provide similar evidence for under-five mortality, which shows a reduction of 14.9 deaths over 10,000 live births (16.3 percent) induced by the government-led information campaign against SIDS.

In Figure 2, we also provide RD estimates for infant and child mortality from all causes except SIDS and other unclassified deaths. The rationale is to eliminate the possibility that any other changes in medical knowledge or technology that occurred during the same period might have differentially affected the health of infants in our treatment group, causing spurious correlation between the new guidelines and infant mortality. Non-SIDS-related infant and child mortality rates in Figure 2 (e) and (f) both exhibit a continuous downward secular trend with no sign of a break around the period of change in sleep recommendation. The RD treatment effect estimates in Table 2 indicate that these secular trends are fully captured by the local linear trend fits. Furthermore, we obtain precisely estimated null effects for both infant and child mortality for all known causes excluding SIDS. The results in Appendix Table C9 also show very small and statistically insignificant estimates on all other unclassified deaths. These results constitute a powerful test of the exclusion restriction because known causes of deaths excluding SIDS still constitute the majority of infant deaths and show no sign of change among cohorts who were exposed to the new sleep guidelines. Therefore, we conclude that our main estimates on infant and child mortality are entirely driven by the government-led public information campaign aimed at changing the sleep position among newborns.

\subsection{Subpopulation Analysis}

Given the well-documented differences in mortality risk based on health at birth and socioeconomic factors, we expect the provision of health knowledge to the population to also differ along these dimensions. Table 3 provides the RD treatment estimates for these subgroups. The results indicate substantial benefits of changing the sleep position for infants with low birthweight and preterm infants. The first panel in Table 3 suggests that the rapid diffusion of new health knowledge saved between 138 and 180 lives per 10,000 births among those with low birth weight and 147 and 194 per 10,000 lives among preterm infants. These are very large absolute effects, and translate into a decrease in the infant mortality rate by 22.4 and 30 percent compared to the baseline mean among the control infants, respectively. These estimates indicate that the information campaign was particularly effective among parents of infants who were born with poor health. The large absolute and relative coefficient sizes further underscore that the policy was also effective in narrowing early life health disparities that start at birth.

Panel II of Table 3 provides the RD estimates for boys and first children only. These results suggest slightly larger effects on boys and somewhat smaller effects on first-born children compared 
to the corresponding estimates for the full population, shown in Table 2 . These results align with the existing medical literature that documents lower baseline infant mortality risk for girls and firstborn siblings. The effect sizes indicate from 13.3-17.6 saved lives per 10,000 boys and a statistically insignificant 8.4-12.8 saved lives per 10,000 first-borns.

Panel III of Table 3 report the estimated coefficients by maternal characteristics. When grouped by mother's education, the subgroup analysis shows that the estimated effects of the information campaign on infant mortality are primarily driven by mothers with relatively few years of education or a vocational education. None of the estimates for infants with mothers with any post-high school degree are statistically different from zero, and coefficient sizes are small. The same coefficients for infants with a mother with basic or vocational education, however, show a consistent improvement in mortality with similar effect sizes; both are slightly larger than the estimated aggregate ITT effects in Table 2. We conclude that the information campaign was most effective among mothers with relatively fewer years of education. Estimates in Table 3 reveal imprecisely estimated but large reductions in infant mortality among children of immigrant mothers. For example, the estimate from the sample with MSE-optimal bandwidth shows 34.9 averted deaths per 10,000 births, corresponding to a 42.8 percent decrease in infant mortality among this demographic group. We show the RD graphs that depicts these estimates in Appendix Figures B3 and B4. Overall, the subgroup analysis shows that providing newly emerged health knowledge was particularly beneficial for those who were susceptible to adverse health outcomes as well as for those with lower socio-economic status and limited access to information.

\subsection{Robustness Tests}

One potential concern is that children who were born several months before the campaign might have benefited from the education campaign, at least partially. For example, an infant born in October 1991 is in our control group, although she could be affected by the new information when she became three months old. The chance of partial treatment is most likely for infants born between September-December 1991 since SIDS risk is highest in the first four months after birth (American Academy of Pediatrics 2011). To test the sensitivity of our result to possible misclassification of treatment status for these infants, we obtained our regression discontinuity estimates from a "donut RD" design in which the birth cohorts born between September 1991 and December 1991 were excluded from the sample. As shown in Appendix Table C4, these results are statistically similar in magnitude to our full sample estimates. Importantly, we find null effects from the same sample when the outcome excludes SIDS and other unclassified deaths. This suggests that in the absence of the policy change, mortality would have been continuous even after removing four monthly birth cohorts around the threshold.

To further assess the sensitivity of our estimates with respect to the threshold date, we run 200 placebo regressions, each using a different cutoff date obtained by moving the month of the guideline change by one month backward and forward in each iteration. We then plot the estimated 
RD coefficients with the 99 percent confidence intervals in Appendix Figure B5. As expected, only two of the 200 arbitrary thresholds provide statistically significant estimates and both of them, by chance, indicate an increase in mortality. The only negative and the largest estimates are obtained around the original cutoff point used in the study.

Next, we evaluate the robustness of our estimates to controlling for covariates, ${ }^{13}$ the kernel used to weight our regressions as well as the the form of the control function in Appendix Tables C3, C5, and C6, respectively. We conduct these robustness checks for all outcomes and bandwidths that are reported in Table 2, which essentially replicates our main results with different regression parameters. To ease the comparison of sensitivity estimates, Figure B6 shows a graphical representation of 150 treatment effect estimates across six outcomes, five bandwidths, and five specifications including the "donut" RD estimates in Appendix Table C4. The gray area in Appendix Figure B6 depicts the MSE-optimal bandwidth range, which constitutes our preferred specifications.

As illustrated in Appendix Table C3, our estimates are robust to controlling for a set of covariates. The results in Appendix Table C5 indicate that using a triangle kernel to weight our regressions makes little difference in our estimates. In Appendix Table C6, we show that the use of a quadratic control function, as is typical in RD studies, provides similar but less precise point estimates. In Appendix Figure B6, we show that none of the choices made in our regression framework produces statistically different estimates. In addition, we show that the point estimates are particularly robust to the Calonico et al. (2019)'s MSE-optimal bandwidth choices. We interpret these results as a further confirmation of the internal validity of our analysis.

Finally, it could be argued that some mothers might have quit smoking in response to the information campaign, which might have then increased the gestational age of their babies, resulting in a potential endogeneity in the date of birth for children who were born after the change in guidelines. The common finding in the literature is that back-to-sleep campaigns in developed countries have successfully altered the sleep position of newborns, but the rates of maternal smoking have virtually unchanged (Cook and Strachan 1999). As shown in appendix Figure B7, smoking does not appear to play a role in explaining our results either. The corresponding empirical test in our case is not straightforward because the data on maternal smoking are not available prior to January 1991. Notwithstanding this limitation, we estimated RD models for smoking relying non-symmetrical bandwidths around the December 31, 1991 cutoff. As shown in Appendix Table $\mathrm{C} 8$, the estimate is small in magnitude and statistically insignificant. The estimates become more precise as we expand the bandwidth on the post-campaign period, though they remain economically insignificant. To further guard against the endogeneity of birth date and gain confidence in our results, in Appendix Table C7, we also report estimates from a fuzzy regression discontinuity design where we construct the running variable using the expected birthday ${ }^{14}$ and use the expected policy exposure as an instrument for the actual policy exposure. Despite adding a fair amount of

\footnotetext{
${ }^{13}$ Covariate-adjusted specifications control for mother's age at birth, gender, month of birth, and birth order fixedeffects, dummy variables for low birth weight, preterm birth, mother's education category and immigrant status.

${ }^{14}$ Calculated by adding 280 to the date of conception.
} 
measurement error to the running variable, our results are still robust to treating the birthdate as endogenous.

\section{Conclusions}

This paper examines the impact of information provision on infant mortality focusing on Denmark's home visiting program. Our results show that the public health information campaign is responsible for one quarter of the decline in infant mortality over the past four decades. ${ }^{15}$ The decrease in infant mortality is entirely driven by a drop in SIDS and other unclassified deaths, which is consistent with the fact that the information campaign mainly aimed at reducing prone infant sleep position. While no data exist to pin down formally the mechanisms for our results, we believe the universality of the campaign with a near perfect take-up rate, the delivery of information through trusted experts, which enables engagement in one-on-one conversations and follow-ups, are key aspects of the Danish campaign that made it so effective (Buus 2001; Hjort et al. 2017). Furthermore, infants with a poorer baseline health and those born to socioeconomically more deprived parents and immigrants experienced stronger benefits in terms of the prevalence of SIDS-related deaths.

To put our results into a broader context, we provide a descriptive comparison of the campaigns implemented in a number of OECD countries. Specifically, we estimate the change in infant mortality between pre- and post-campaign net of linear trends using annual data. As we show in Appendix Figure B8 and Table C10, the top three countries that experienced the largest relative drop in infant mortality following a campaign are Norway, Denmark, and Sweden. These countries have in common that they have a universal health care system and that information on sleeping position is primarily delivered to the new parents through a direct and one-to-one interaction between home visiting nurses and the new parents, either at the residences of the new mothers, as in the case of Denmark and Norway, or local infant care clinics, as in the case of Sweden (Alm et al. 2004). The results from this analysis lend further support to the notion that comprehensive, universally accessible public information campaigns involving direct contact between mothers and the public health officials are likely key to the success of such programs.

Despite the breakthroughs in medical technology and developments in new treatments, a significant number of children continue to die every year, not because of a lack of access to advanced technology or effective treatments, but due to continued infant-care practices that place children at a higher risk of death. For example, SIDS, which can be prevented by simple parental actions, constitutes the leading cause of death among infants between one month and one year of age in the United States. It is also one of the leading sources of ethnic and racial inequality in child survival. In 2015, for example, prevalence of nonsupine sleep position among black children

\footnotetext{
${ }^{15}$ Between 1979 and 2019, infant mortality decreased from 8.5 to 3.2 per 1,000 in Denmark, whereas our preferred estimate of the policy impact is 1.32 , which roughly corresponds to $\frac{1.32}{(8.5-3.2)} \approx 25 \%$ of the overall decrease.
} 
was almost 38 percent, that is 16 percentage points higher than their white peers (Bombard et al. 2018). Not surprisingly, ethnic and racial disparities in child care are also directly reflected in SIDS rates. In fact, similar persistent and even growing divergencies in health by socioeconomic status are emerging in developed countries, including those with universal health insurance programs (Elo and Preston 1996; Pappas et al. 1993; Mackenbach et al. 2003). Due to incremental changes in medical technology, health behaviors are playing a decisive role in increasing health disparities. The results of this paper represent a clear demonstration that well-targeted behavioral interventions implemented at scale can effectively reduce health disparities that tend to persist despite better technology and access to healthcare. 


\section{References}

Alm, Bernt, Göran Wennergren, Laslo Erdes, Per Möllborg, Rolf Pettersson, Nils Åberg, and S Gunnar Norvenius, "Föräldrar har tagit till sig råden för att förebygga plötslig spädbarnsdöd," Läkartidningen, 2004, 101, 1268-70.

Alsan, Marcella and Claudia Goldin, "Watersheds in child mortality: the role of effective water and sewerage infrastructure, 1880-1920," Journal of Political Economy, 2019, 127 (2), 586-638.

American Academy of Pediatrics, "SIDS and Other Sleep-Related Infant Deaths: Expansion of Recommendations for a Safe Infant Sleeping Environment," Pediatrics, 2011, 128 (5), e1341-e1367.

Anderson, D Mark, Kerwin Kofi Charles, and Daniel I Rees, "Re-examining the contribution of public health efforts to the decline in urban mortality," American Economic Journal: Applied Economics, 2020.

_, , , Claudio Las Heras Olivares, and Daniel I Rees, "Was the first public health campaign successful?," American Economic Journal: Applied Economics, 2019, 11 (2), 143-75.

Anderson, D. Mark, Kerwin Kofi Charles, Daniel I. Rees, and Tianyi Wang, "Water purification efforts and the black-white infant mortality gap, 1906-1938," Journal of Urban Economics, 2021, $122,103329$.

Anderson, D Mark, Ryan Brown, Kerwin Kofi Charles, and Daniel I Rees, "Occupational licensing and maternal health: Evidence from early midwifery laws," Journal of Political Economy, 2020, 128 (11), 4337-4383.

Bhalotra, Sonia, Martin Karlsson, and Therese Nilsson, "Infant health and longevity: Evidence from a historical intervention in Sweden," Journal of the European Economic Association, 2017, 15 (5), 1101-1157.

Bombard, Jennifer M, Katherine Kortsmit, Lee Warner, Carrie K Shapiro-Mendoza, Shanna Cox, Charlan D Kroelinger, Sharyn E Parks, Deborah L Dee, Denise V D'Angelo, Ruben A Smith et al., "Vital signs: Trends and disparities in infant safe sleep practices-United States, 2009-2015," Morbidity and Mortality Weekly Report, 2018, 67 (1), 39.

Bütikofer, Aline, Katrine V Løken, and Kjell G Salvanes, "Infant health care and long-term outcomes," Review of Economics and Statistics, 2019, 101 (2), 341-354.

Buus, Henriette, "Sundhedsplejerskeinstitutionens dannelse," En kulturteoretisk og kulturhistorisk analyse af velfærdsstatens embedsværk, 2001.

Calonico, Sebastian, Matias D. Cattaneo, Max H. Farrell, and Rocio Titiunik, "Regression Discontinuity Designs Using Covariates," Review of Economics and Statistics, 2019, 101 (3), 442-451. 
Carlin, Rebecca F and Rachel Y Moon, "Risk factors, protective factors, and current recommendations to reduce sudden infant death syndrome: a review," JAMA pediatrics, 2017, 171 (2), 175-180.

Chen, Alice, Emily Oster, and Heidi Williams, "Why is infant mortality higher in the United States than in Europe?," American Economic Journal: Economic Policy, 2016, 8 (2), 89-124.

Cook, Derek G and David P Strachan, "Summary of effects of parental smoking on the respiratory health of children and implications for research," Thorax, 1999, 54 (4), 357-366.

Cutler, David and Grant Miller, "The role of public health improvements in health advances: the twentieth-century United States," Demography, 2005, 42 (1), 1-22.

— ,Angus Deaton, and Adriana Lleras-Muney, "The determinants of mortality," Journal of economic perspectives, 2006, 20 (3), 97-120.

Danish National Board of Health , "Retningslinier for tilrettelæggelse af sundhedsplejeordninger," https://dsr.dk/sites/default/files/473/retningslinjer_for_tilrettelaeggelse_a f_sundhedsplejerskeordninger_1985.pdf 1985. Online; accessed January 14, 2022.

Danish Nurses' Organization, "Sundhedspleje I 80 år - 1938-2018," https://dsr.dk/sites/d efault/files/473/sundhedsplejens_historie_low.pdf 2018. Online; accessed January 14, 2022.

de Walque, Damien, "How does the impact of an HIV/AIDS information campaign vary with educational attainment? Evidence from rural Uganda," Journal of Development Economics, 2007, $84(2), 686-714$.

_ ,"Education, information, and smoking decisions evidence from smoking histories in the United States, 1940-2000," Journal of Human Resources, 2010, 45 (3), 682-717.

Deaton, Angus, “The great escape: A review of robert fogel's the escape from hunger and premature death, 1700-2100," Journal of Economic Literature, 2006, 44 (1), 106-114.

Dupas, Pascaline, "Do teenagers respond to HIV risk information? Evidence from a field experiment in Kenya," American Economic Journal: Applied Economics, 2011, 3 (1), 1-34.

Dwyer, T. and A.-L. Ponsonby, "Sudden Infant Death Syndrome and Prone Sleeping Position," Annals of Epidemiology, 2009, 19 (4), 245-249.

Dwyer, Terence, A-LB Ponsonby, Neville M Newman, and Laura E Gibbons, "Prospective cohort study of prone sleeping position and sudden infant death syndrome," The Lancet, 1991, 337 (8752), 1244-1247. 
_ , Anne-Louise Ponsonby, Leigh Blizzard, Neville M Newman, and Jennifer A Cochrane, "The contribution of changes in the prevalence of prone sleeping position to the decline in sudden infant death syndrome in Tasmania," Jama, 1995, 273 (10), 783-789.

Elo, Irma T and Samuel H Preston, "Educational differentials in mortality: United States, 19791985," Social science E medicine, 1996, 42 (1), 47-57.

Feigenbaum, James J, Christopher Muller, and Elizabeth Wrigley-Field, "Regional and racial inequality in infectious disease mortality in US cities, 1900-1948," Demography, 2019, 56 (4), 1371-1388.

Fleming, Peter J, Ruth Gilbert, Yehu Azaz, P Jeremy Berry, Peter T Rudd, Alison Stewart, and Elizabeth Hall, "Interaction between bedding and sleeping position in the sudden infant death syndrome: a population based case-control study.," British Medical Journal, 1990, 301 (6743), 85-89.

Goldstein, Richard D, Felicia L Trachtenberg, Mary Ann Sens, Brian J Harty, and Hannah C Kinney, “Overall postneonatal mortality and rates of SIDS," Pediatrics, 2016, 137 (1).

Guldager, E., “Spædbørns søvn, Sovevaner, Vuggedød, Sundhedsplejerskens opgaver," Sundhedsplejersken, tema nr. 1 Særnummer April 19921992.

_ , H. Kjærgaard-Nielsen, and V. Weirum Knudsen, "Barn i vente," Sundhedsstyrelsen og komiteen for sundhedsoplysning 1990.

Hauck, Fern and Kawai O Tanabe, "International trends in sudden infant death syndrome and other sudden unexpected deaths in infancy: need for better diagnostic standardization," Current Pediatric Reviews, 2010, 6 (1), 95-101.

Hauck, Fern R and Kawai O Tanabe, "International trends in sudden infant death syndrome: stabilization of rates requires further action," Pediatrics, 2008, 122 (3), 660-666.

Helweg-Larsen, K and E. Guldager, "Sundhedsstyrelsens kampagne mod vuggedød," Sygeplejersken, 2001, (31), 30-31.

_ and _ , "Vuggedød - et historisk tilbageblik," Sygeplejersken, 2001, (31), 30-31.

_ and _, "Vuggedød - hvad ved vi i dag og hvordan kan vi yderligere reducere antallet?," Månedsskrift Praktiserende Lægegerning, 2001, pp. 203-218.

Helweg-Larsen, Karin, "The Danish register of causes of death," Scandinavian journal of public health, 2011, 39 (7_suppl), 26-29.

_ , Lisbeth B Knudsen, Markil Gregersen, and Jørn Simonsen, "Sudden infant death syndrome (SIDS) in Denmark: evaluation of the increasing incidence of registered SIDS in the period 1972 to 1983 and results of a prospective study in 1987 through 1988," Pediatrics, 1992, 89 (5), 855-859. 
Hjort, Jonas et al., "Universal investment in infants and long-run health: evidence from Denmark's 1937 home visiting program," American Economic Journal: Applied Economics, 2017, 9 (4), 78-104.

Horne, Rosemary SC, Dorota Ferens, Anne-Maree Watts, Jessica Vitkovic, Brendan Lacey, Sarah Andrew, Susan M Cranage, Bonnie Chau, and T Michael Adamson, "The prone sleeping position impairs arousability in term infants," The Journal of pediatrics, 2001, 138 (6), 811-816.

Horton, Sue and Richard H Steckel, "Malnutrition: global economic losses attributable to malnutrition 1900-2000 and projections to 2050," How Much Have Global Problems Cost the Earth? A Scorecard from 1900 to, 2013, 2050, 247-272.

Hussam, Reshmaan Nahar, Atonu Rabbani, Giovanni Reggiani, and Natalia Rigol, "Habit formation and rational addiction: A field experiment in handwashing," Harvard Business School working paper series\# 18-030, 2017.

Jonge, GA De, AC Engelberts, AJ Koomen-Liefting, and PJ Kostense, "Cot death and prone sleeping position in The Netherlands.," BMJ: British Medical Journal, 1989, 298 (6675), 722.

Kamerman, Sheila B and Alfred J Kahn, "Home health visiting in Europe," The Future of Children, 1993, pp. 39-52.

Komisarow, Sarah, "Public health regulation and mortality: Evidence from early 20th century milk laws," Journal of health economics, 2017, 56, 126-144.

Loewenstein, George, Joseph Price, and Kevin Volpp, "Habit formation in children: Evidence from incentives for healthy eating," Journal of health economics, 2016, 45, 47-54.

Lov om Sundhedsplejerske Ordningerne, Lov nr 409 af 13. juni 1973

Lov om Sundhedsplejerske Ordningerne, Lov nr 409 af 13. juni 1973, https://www .retsinform ation.dk/eli/lta/1973/409. Online; accessed January 14, 2022.

MacDorman, Marian F, Donna L Hoyert, and TJ Mathews, Recent declines in infant mortality in the United States, 2005-2011 number 120, US Department of Health and Human Services, Centers for Disease Control and ..., 2013.

Mackenbach, Johan P, Vivian Bos, Otto Andersen, Mario Cardano, Giuseppe Costa, Seeromanie Harding, Alison Reid, Örjan Hemström, Tapani Valkonen, and Anton E Kunst, "Widening socioeconomic inequalities in mortality in six Western European countries," International journal of epidemiology, 2003, 32 (5), 830-837.

Matthiessen, Poul Christian, Infant and Perinatal Mortality in Denmark: Statistical Description and Analysis of Long-term Trends in Stillbirth, Infant, and Perinatal Mortality in Denmark... number 9, US Department of Health, Education, and Welfare, Public Health Service, 1967. 
Meckel, Richard A, Save the babies: American public health reform and the prevention of infant mortality, 1850-1929, Vol. 32, University of Michigan Press, 1998.

Miller, Neil Z and Gary S Goldman, "Infant mortality rates regressed against number of vaccine doses routinely given: Is there a biochemical or synergistic toxicity?," Human E Experimental Toxicology, 2011, 30 (9), 1420-1428.

Mitchell, EA, R Scragg, AW Stewart, DM Becroft, BJ Taylor, RP Ford, IB Hassall, DM Barry, EM Allen, and AP Roberts, "Results from the first year of the New Zealand cot death study.," The New Zealand medical journal, 1991, 104 (906), 71-76.

Moehling, Carolyn $\mathbf{M}$ and Melissa A Thomasson, "Saving babies: The impact of public education programs on infant mortality," Demography, 2014, 51 (2), 367-386.

Møller, L., L. Iversen, and B. Witt, "Pludselig uventet spædbørnsdød - en screening af risikofaktorer $i$ dem danske amter," Sygeplejersken, 1994, (94), 18-21.

Olds, David L, Harriet Kitzman, Carole Hanks, Robert Cole, Elizabeth Anson, Kimberly SidoraArcoleo, Dennis W Luckey, Charles R Henderson, John Holmberg, Robin A Tutt et al., "Effects of nurse home visiting on maternal and child functioning: age-9 follow-up of a randomized trial," Pediatrics, 2007, 120 (4), e832-e845.

Oster, Emily, Cribsheet: A data-driven guide to better, more relaxed parenting, from birth to preschool, Penguin Books, 2020.

Pappas, Gregory, Susan Queen, Wilbur Hadden, and Gail Fisher, "The increasing disparity in mortality between socioeconomic groups in the United States, 1960 and 1986," New England journal of medicine, 1993, 329 (2), 103-109.

Ponsonby, Anne-Louise, Terence Dwyer, Laura E Gibbons, Jennifer A Cochrane, and You-Gan Wang, "Factors potentiating the risk of sudden infant death syndrome associated with the prone position," New England Journal of Medicine, 1993, 329 (6), 377-382.

Sixhøj, Hanne, "Sundhedspleje - et tilbud om Kontrol. Om sundhedsplejerskers implicitte opfattelse af sundhedspleje: sundhedsfremme eller forebyggelse?," Institut for Sygeplejevidenskab. Det sundhedsfaglige fakultet. Fakultet ved Århus Universitet 2001.

Sonne, SK, "Indvandrerfamilie og spædbarnspleje - et vanskeligt møde mellem kulturer og traditioner - En brugerundersøgelse i Københavns Kommune," København: Socialdirektoratet 1994.

Ward, John W and Christian Warren, Silent victories: the history and practice of public health in twentieth-century America, Oxford University Press, 2006.

Watson, Tara, "Public health investments and the infant mortality gap: Evidence from federal sanitation interventions on US Indian reservations," Journal of Public Economics, 2006, 90 (8-9), 1537-1560. 
Weiss, Janet A and Mary Tschirhart, "Public information campaigns as policy instruments," Journal of policy analysis and management, 1994, 13 (1), 82-119.

Wennergren, G, B Aim, N Øyen, K Helweg-Larsen, J Milerad, R Skjaerven, SG Norvenius, H Lagercrantz, M Wennborg, AK Daltveit et al., "The decline in the incidence of SIDS in Scandinavia and its relation to risk-intervention campaigns," Acta Paediatrica, 1997, 86 (9), 963-968.

Wüst, Miriam, "Early interventions and infant health: Evidence from the Danish home visiting program," Labour Economics, 2012, 19 (4), 484-495. 
Figure 1: TRENDS IN INFANT MORTALITY

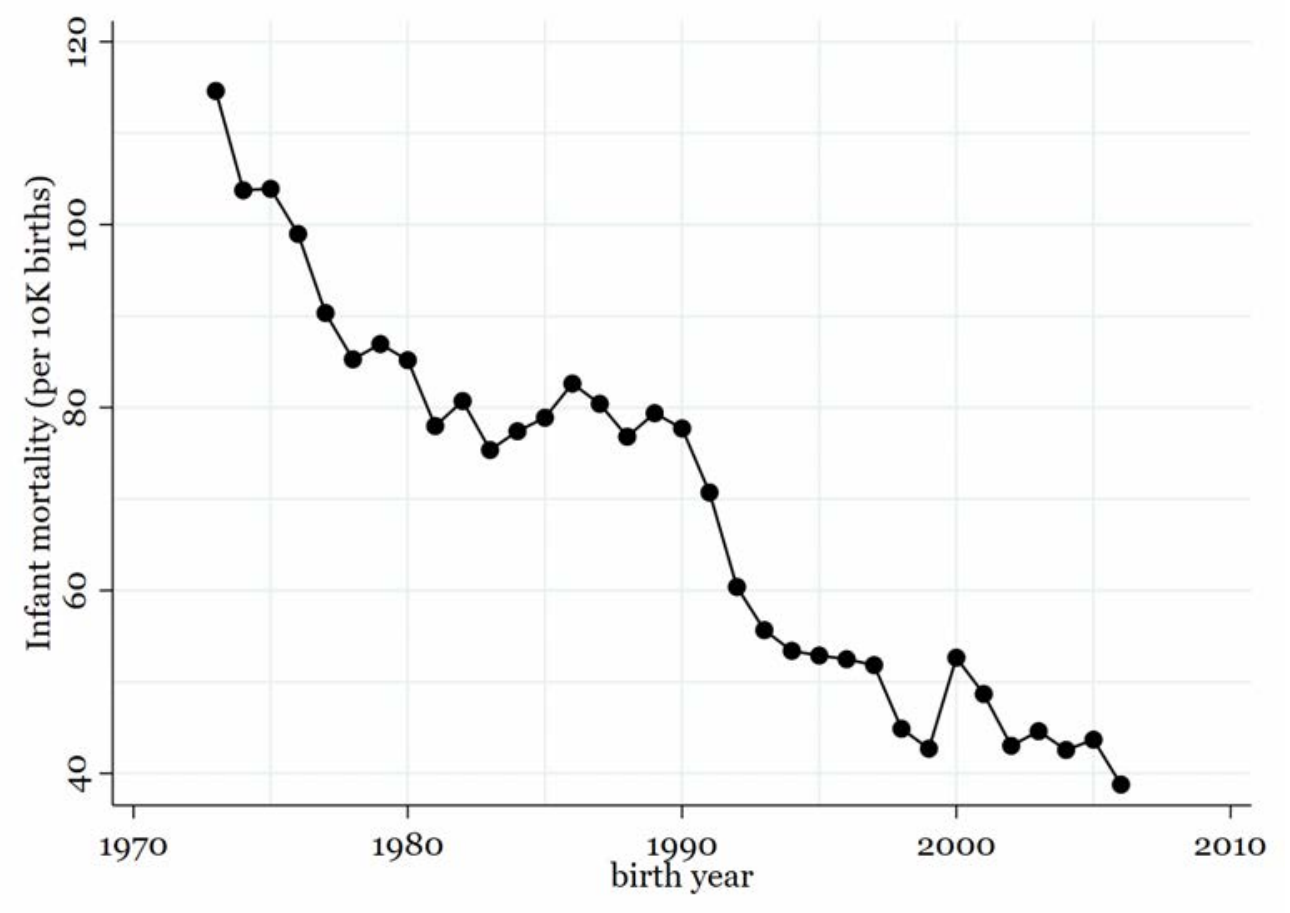

(A) All-cause infant mortality rate

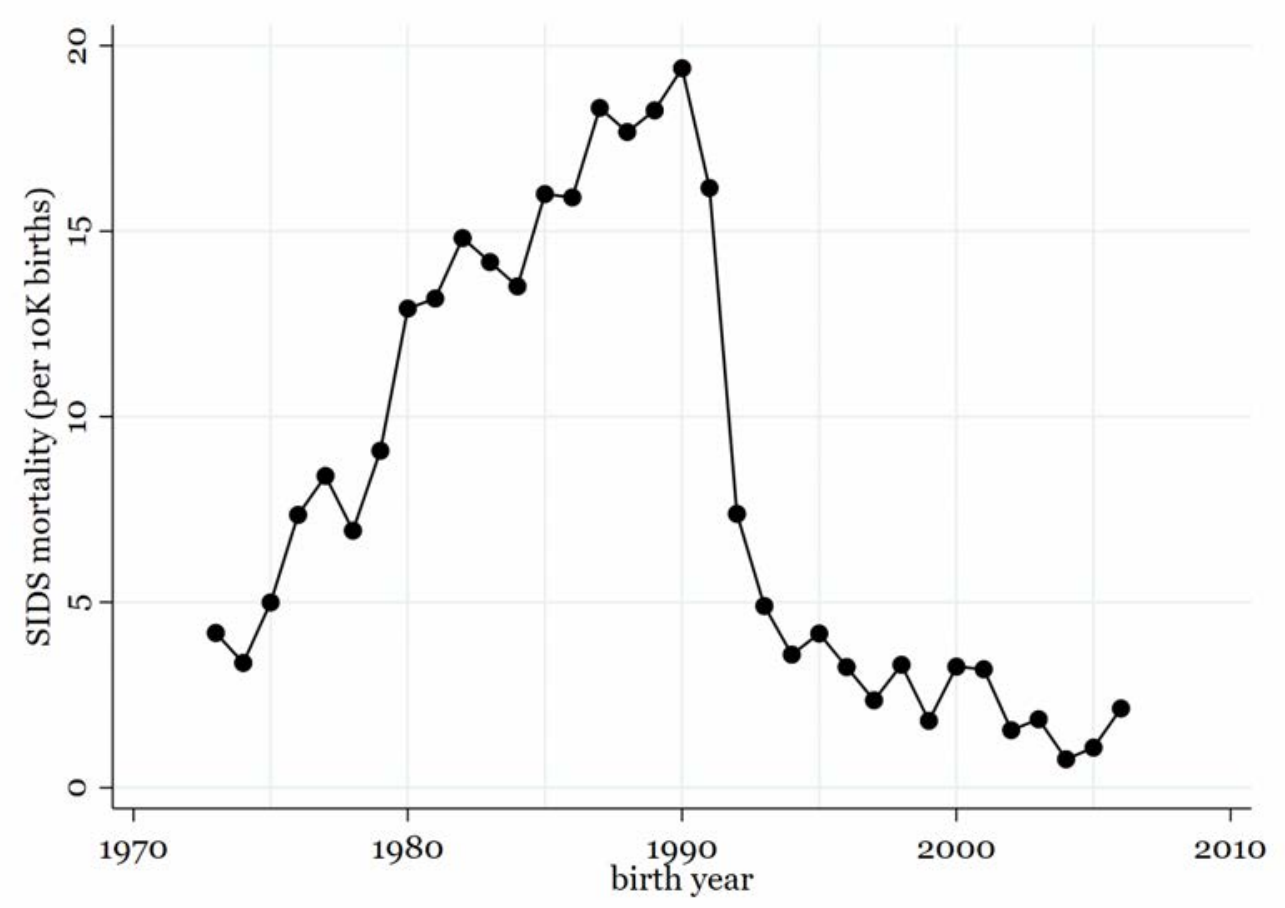

(в) SIDS mortality rate 
Figure 2: RD estimates on Infant and Child Mortality

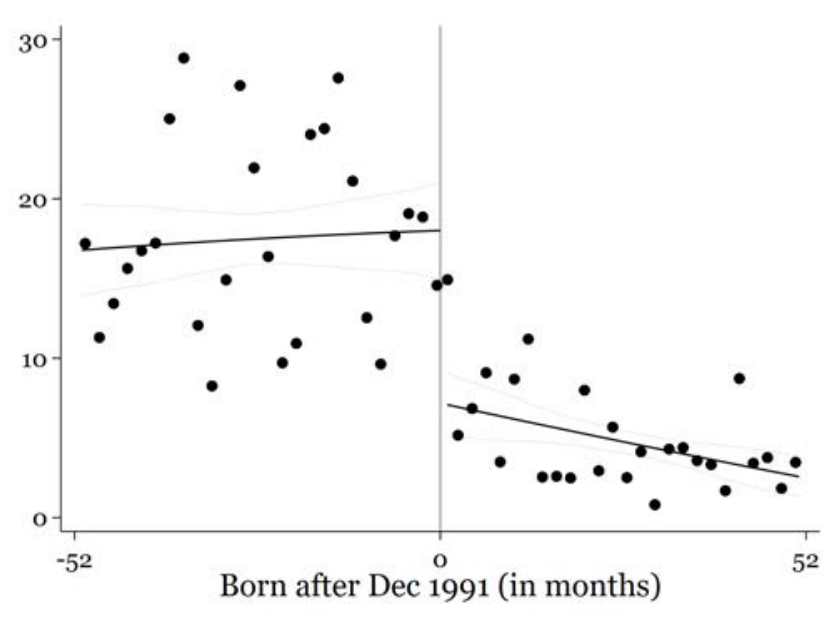

(A) SIDS mortality

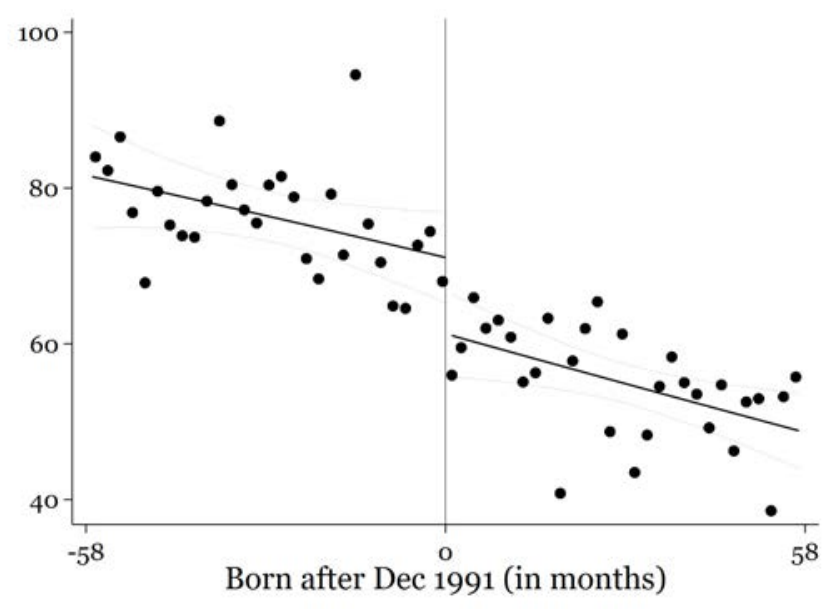

(c) Infant mortality

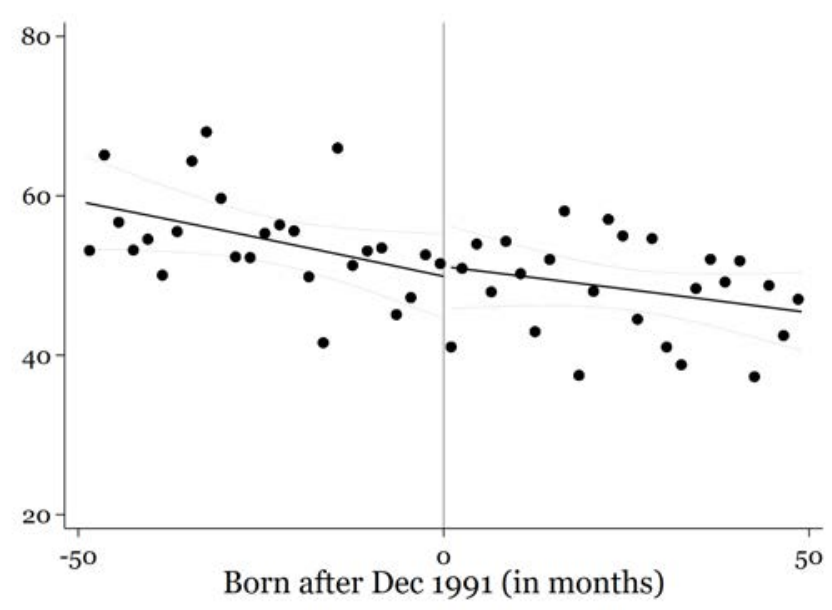

(E) Infant mortality excluding SIDS + unknown

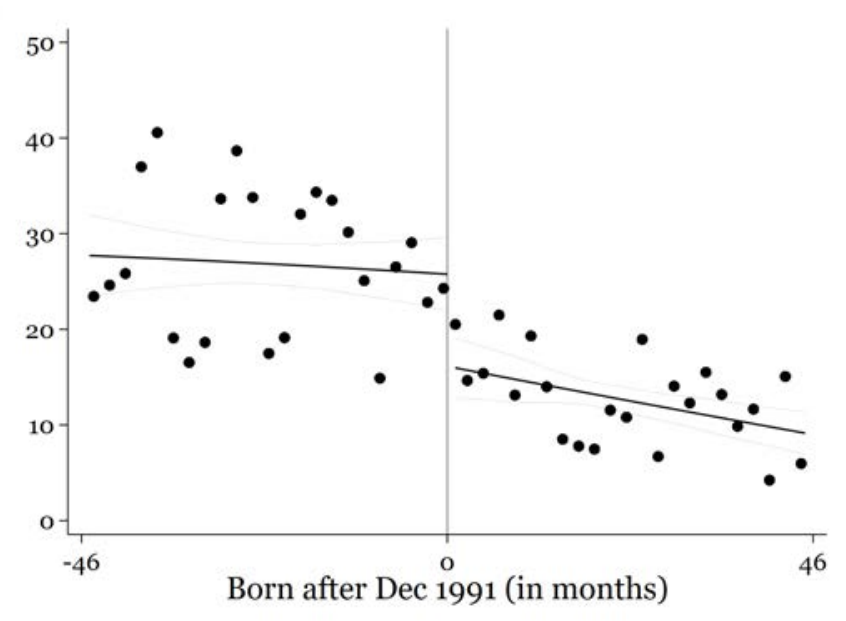

(в) SIDS + all unclassified mortality

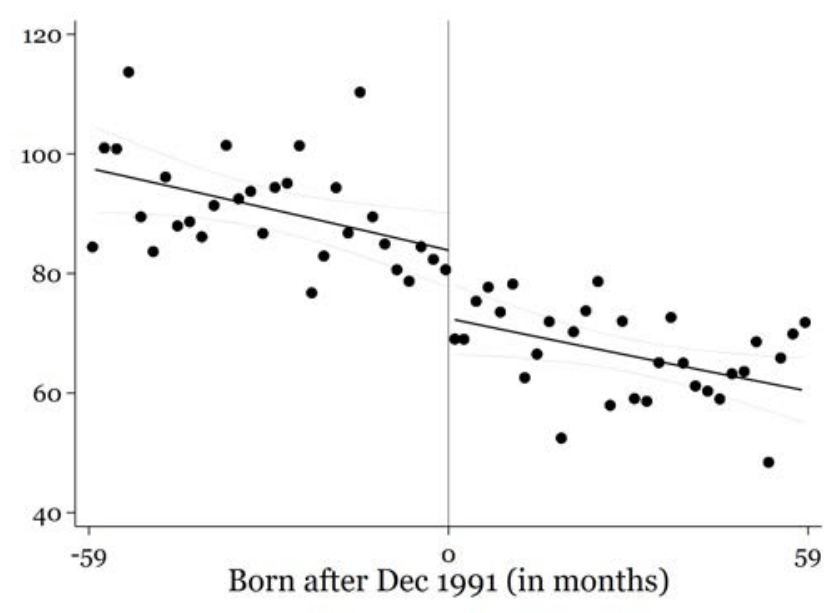

(D) Child mortality

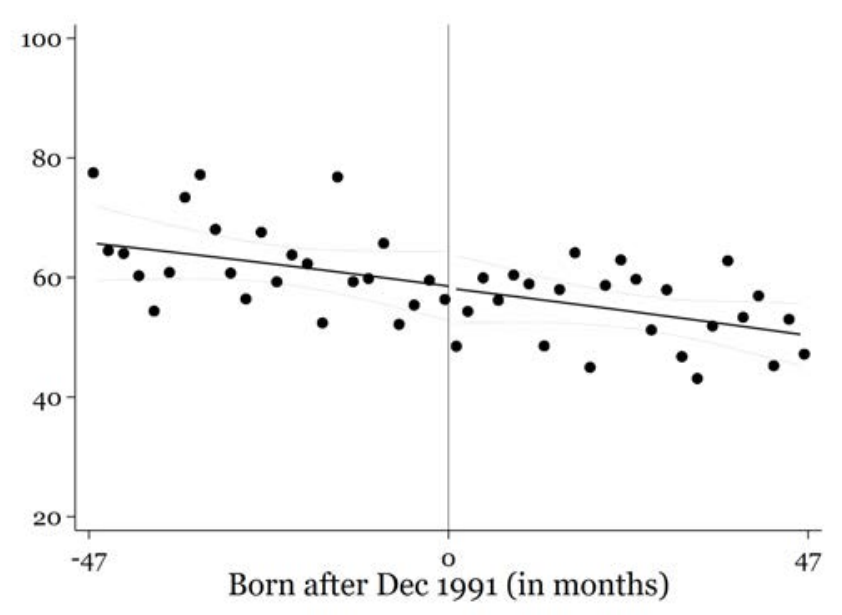

(F) Child mortality excluding SIDS + unknown 


\section{TABle 1: Balance of Covariates}

\begin{tabular}{|c|c|c|c|c|c|c|}
\hline & MSE-optimal & \pm 1000 & \pm 1250 & \pm 1500 & \pm 1750 & \pm 2000 \\
\hline \multicolumn{7}{|l|}{ Female } \\
\hline \multirow[t]{2}{*}{ Born after Dec 1991} & -0.001 & -0.002 & -0.002 & -0.001 & -0.001 & 0.000 \\
\hline & $(0.003)$ & $(0.003)$ & $(0.003)$ & $(0.003)$ & $(0.003)$ & $(0.002)$ \\
\hline Bandwidth & 1780 & 1000 & 1250 & 1500 & 1750 & 2000 \\
\hline Observations & 630529 & 359982 & 447560 & 534232 & 620660 & 704098 \\
\hline Control group mean & 0.49 & 0.49 & 0.49 & 0.49 & 0.49 & 0.49 \\
\hline \multicolumn{7}{|l|}{ Birth order } \\
\hline \multirow[t]{2}{*}{ Born after Dec 1991} & $0.016^{* * *}$ & $0.023^{* * *}$ & $0.014^{* *}$ & $0.019^{* * *}$ & $0.022^{* * *}$ & $0.025^{* * *}$ \\
\hline & $(0.005)$ & $(0.006)$ & $(0.006)$ & $(0.005)$ & $(0.005)$ & $(0.004)$ \\
\hline Bandwidth & 1359 & 1000 & 1250 & 1500 & 1750 & 2000 \\
\hline Observations & 488403 & 360502 & 448200 & 535007 & 621589 & 705141 \\
\hline Control group mean & 1.74 & 1.74 & 1.74 & 1.74 & 1.74 & 1.74 \\
\hline \multicolumn{7}{|l|}{ Low birthweight } \\
\hline \multirow{2}{*}{ Born after Dec 1991} & 0.002 & 0.001 & 0.002 & 0.002 & 0.001 & 0.001 \\
\hline & $(0.001)$ & $(0.002)$ & $(0.002)$ & $(0.001)$ & $(0.001)$ & $(0.001)$ \\
\hline Bandwidth & 1436 & 1000 & 1250 & 1500 & 1750 & 2000 \\
\hline Observations & 512613 & 358827 & 446100 & 532610 & 618893 & 701600 \\
\hline Control group mean & 0.05 & 0.05 & 0.05 & 0.05 & 0.05 & 0.05 \\
\hline \multicolumn{7}{|l|}{ Preterm birth } \\
\hline \multirow[t]{2}{*}{ Born after Dec 1991} & 0.003 & 0.002 & 0.002 & $0.003^{*}$ & 0.001 & $0.002^{* *}$ \\
\hline & $(0.002)$ & $(0.002)$ & $(0.002)$ & $(0.001)$ & $(0.001)$ & $(0.001)$ \\
\hline Bandwidth & 1197 & 1000 & 1250 & 1500 & 1750 & 2000 \\
\hline Observations & 424742 & 356950 & 443659 & 529939 & 615914 & 695590 \\
\hline Control group mean & 0.05 & 0.05 & 0.05 & 0.05 & 0.05 & 0.05 \\
\hline \multicolumn{7}{|l|}{ Mother's age at birth } \\
\hline \multirow[t]{2}{*}{ Born after Dec 1991} & 0.033 & 0.018 & 0.033 & 0.033 & $0.052^{* *}$ & $0.055^{* *}$ \\
\hline & $(0.028)$ & $(0.033)$ & $(0.03)$ & $(0.027)$ & $(0.025)$ & $(0.023)$ \\
\hline Bandwidth & 1367 & 1000 & 1250 & 1500 & 1750 & 2000 \\
\hline Observations & 491321 & 360502 & 448200 & 535007 & 621589 & 705141 \\
\hline Control group mean & 27.82 & 27.89 & 27.84 & 27.79 & 27.75 & 27.7 \\
\hline \multicolumn{7}{|l|}{ Mother with basic education } \\
\hline \multirow[t]{2}{*}{ Born after Dec 1991} & 0.001 & 0.002 & 0.002 & 0.000 & 0.000 & 0.000 \\
\hline & $(0.003)$ & $(0.003)$ & $(0.003)$ & $(0.003)$ & $(0.002)$ & $(0.002)$ \\
\hline Bandwidth & 1376 & 1000 & 1250 & 1500 & 1750 & 2000 \\
\hline Observations & 493258 & 359629 & 447113 & 533645 & 619986 & 703224 \\
\hline Control group mean & 0.34 & 0.33 & 0.33 & 0.34 & 0.34 & 0.35 \\
\hline \multicolumn{7}{|l|}{ Mother with further education } \\
\hline \multirow[t]{2}{*}{ Born after Dec 1991} & -0.001 & -0.003 & -0.002 & -0.001 & -0.002 & -0.003 \\
\hline & $(0.003)$ & $(0.003)$ & $(0.003)$ & $(0.002)$ & $(0.002)$ & $(0.002)$ \\
\hline Bandwidth & 1373 & 1000 & 1250 & 1500 & 1750 & 2000 \\
\hline Observations & 492254 & 359629 & 447113 & 533645 & 619986 & 703224 \\
\hline Control group mean & 0.26 & 0.26 & 0.26 & 0.26 & 0.26 & 0.26 \\
\hline \multicolumn{7}{|l|}{ Mother immigrant } \\
\hline \multirow[t]{2}{*}{ Born after Dec 1991} & 0.001 & 0.000 & 0.002 & 0.002 & 0.001 & -0.001 \\
\hline & $(0.002)$ & $(0.002)$ & $(0.002)$ & $(0.002)$ & $(0.001)$ & $(0.001)$ \\
\hline Bandwidth & 1046 & 1000 & 1250 & 1500 & 1750 & 2000 \\
\hline Observations & 376252 & 359629 & 447113 & 533645 & 619986 & 703224 \\
\hline Control group mean & 0.08 & 0.08 & 0.08 & 0.08 & 0.07 & 0.07 \\
\hline
\end{tabular}

Notes: Table shows the regression discontinuity estimates for the effect of public health information campaign on predetermined covariates. See Appendix Table C1 for the variable definitions. Each column indicates the bandwidth used to restrict the regression sample. Standard errors are clustered at the birthday level and are shown in parentheses. Significance levels are indicated by ${ }^{* * *}<0.01, * *<0.05$, and ${ }^{*}<0.1$. 


\section{Table 2: Effect of Guideline Changes on Infant and Child Mortality}

\begin{tabular}{|c|c|c|c|c|c|c|}
\hline & MSE-optimal & \pm 1000 & \pm 1250 & \pm 1500 & \pm 1750 & \pm 2000 \\
\hline \multicolumn{7}{|l|}{ SIDS Mortality } \\
\hline Born after Dec 1991 & $\begin{array}{c}-11.666^{* * *} \\
(1.88)\end{array}$ & $\begin{array}{c}-10.415^{* * *} \\
(2.336)\end{array}$ & $\begin{array}{l}-9.87^{* * *} \\
(2.123)\end{array}$ & $\begin{array}{c}-11.732^{* * *} \\
(1.915)\end{array}$ & $\begin{array}{c}-11.433^{* * *} \\
(1.782)\end{array}$ & $\begin{array}{c}-10.993 * * * \\
(1.667)\end{array}$ \\
\hline Bandwidth & 1554 & 1000 & 1250 & 1500 & 1750 & 2000 \\
\hline Observations & 553020 & 360502 & 448200 & 535007 & 621589 & 705141 \\
\hline Control group mean & 17.72 & 17.89 & 18.33 & 17.71 & 18.04 & 18.17 \\
\hline \multicolumn{7}{|c|}{ SIDS + All Unclassified Mortality } \\
\hline Born after Dec 1991 & $\begin{array}{c}-9.887^{* * * *} \\
(2.613)\end{array}$ & $\begin{array}{c}-10.127^{* * *} \\
(2.994)\end{array}$ & $\begin{array}{c}-9.193^{* * *} \\
(2.711)\end{array}$ & $\begin{array}{c}-11.225^{* * *} \\
(2.462)\end{array}$ & $\begin{array}{c}-11.676^{* * * *} \\
(2.294)\end{array}$ & $\begin{array}{c}-11.006^{* * *} \\
(2.161)\end{array}$ \\
\hline Bandwidth & 1334 & 1000 & 1250 & 1500 & 1750 & 2000 \\
\hline Observations & 479110 & 360502 & 448200 & 535007 & 621589 & 705141 \\
\hline Control group mean & 27.13 & 26.64 & 27.26 & 26.54 & 27.04 & 27.41 \\
\hline \multicolumn{7}{|l|}{ Infant Mortality } \\
\hline Born after Dec 1991 & $\begin{array}{c}-13.23^{* * *} \\
(4.107)\end{array}$ & $\begin{array}{c}-11.643^{* *} \\
(5.508)\end{array}$ & $\begin{array}{c}-12.222^{* *} \\
(4.969)\end{array}$ & $\begin{array}{c}-13.155^{* * *} \\
(4.496)\end{array}$ & $\begin{array}{c}-13.454^{* * *} \\
(4.149)\end{array}$ & $\begin{array}{c}-12.98^{* * *} \\
(3.923)\end{array}$ \\
\hline Bandwidth & 1799 & 1000 & 1250 & 1500 & 1750 & 2000 \\
\hline Observations & 637804 & 360502 & 448200 & 535007 & 621589 & 705141 \\
\hline Control group mean & 76.82 & 75.61 & 76.21 & 76.04 & 76.72 & 77.98 \\
\hline \multicolumn{7}{|l|}{ Child Mortality } \\
\hline Born after Dec 1991 & $\begin{array}{c}-14.878^{* * *} \\
(4.524)\end{array}$ & $\begin{array}{c}-12.419^{* *} \\
(6.073)\end{array}$ & $\begin{array}{c}-13.482^{* *} \\
(5.474)\end{array}$ & $\begin{array}{c}-13.919^{* * *} \\
(4.963)\end{array}$ & $\begin{array}{c}-14.142^{* * *} \\
(4.604)\end{array}$ & $\begin{array}{c}-13.462^{* * *} \\
(4.328)\end{array}$ \\
\hline Bandwidth & 1818 & 1000 & 1250 & 1500 & 1750 & 2000 \\
\hline Observations & 643921 & 360502 & 448200 & 535007 & 621589 & 705141 \\
\hline Control group mean & 91.37 & 89.36 & 89.77 & 89.81 & 91.18 & 92.54 \\
\hline \multicolumn{7}{|c|}{ Infant mortality excluding SIDS } \\
\hline Born after Dec 1991 & $\begin{array}{l}-0.913 \\
(3.885)\end{array}$ & $\begin{array}{c}-0.32 \\
(4.787)\end{array}$ & $\begin{array}{l}-1.495 \\
(4.31)\end{array}$ & $\begin{array}{l}-0.775 \\
(3.926)\end{array}$ & $\begin{array}{l}-0.861 \\
(3.632)\end{array}$ & $\begin{array}{c}-1.07 \\
(3.432)\end{array}$ \\
\hline Bandwidth & 1533 & 1000 & 1250 & 1500 & 1750 & 2000 \\
\hline Observations & 545897 & 360502 & 448200 & 535007 & 621589 & 705141 \\
\hline Control group mean & 54.94 & 54.2 & 54.42 & 54.94 & 55.41 & 56.36 \\
\hline \multicolumn{7}{|c|}{ Child mortality excluding SIDS } \\
\hline Born after Dec 1991 & $\begin{array}{c}-2.79 \\
(4.342)\end{array}$ & $\begin{array}{l}-2.292 \\
(5.183)\end{array}$ & $\begin{array}{l}-4.289 \\
(4.655)\end{array}$ & $\begin{array}{l}-2.695 \\
(4.242)\end{array}$ & $\begin{array}{l}-2.466 \\
(3.94)\end{array}$ & $\begin{array}{l}-2.456 \\
(3.707)\end{array}$ \\
\hline Bandwidth & 1423 & 1000 & 1250 & 1500 & 1750 & 2000 \\
\hline Observations & 510634 & 360502 & 448200 & 535007 & 621589 & 705141 \\
\hline Control group mean & 63.17 & 62.72 & 62.51 & 63.26 & 64.14 & 65.14 \\
\hline
\end{tabular}

Notes: Table shows the regression discontinuity estimates for the effect of public health information campaign on infant and child mortality. Effect sizes and outcome means are expressed per 10 thousand live births. See the Appendix Table $\mathrm{C} 1$ for the variable definitions. Each column indicates the bandwidth used to restrict the regression sample. Standard errors are clustered at the birthday level, and are shown in parentheses. Significance levels are indicated by $* * *<0.01, * *<0.05$, and ${ }^{*}<0.1$. 
Table 3: RD Effects of Guideline Changes on Infant Mortality. Subgroup Analysis

\begin{tabular}{|c|c|c|c|c|c|c|}
\hline & MSE-optimal & \pm 1000 & \pm 1250 & \pm 1500 & \pm 1750 & \pm 2000 \\
\hline \multicolumn{7}{|l|}{$\begin{array}{l}\text { I. Child's Health at birth } \\
\text { Low birth weight }\end{array}$} \\
\hline Born after Dec. 1991 & $\begin{array}{l}-151.093^{* * *} \\
(51.957)\end{array}$ & $\begin{array}{l}-137.567^{*} \\
(70.208)\end{array}$ & $\begin{array}{l}-170.288^{* * *} \\
(63.495)\end{array}$ & $\begin{array}{l}-180.178^{* * *} \\
(58.092)\end{array}$ & $\begin{array}{c}-144.219^{* * *} \\
(54.019)\end{array}$ & $\begin{array}{c}-137.334^{* * *} \\
(51.003)\end{array}$ \\
\hline Bandwidth & 1942 & 1000 & 1250 & 1500 & 1750 & 2000 \\
\hline Observations & 34994 & 18331 & 22771 & 27344 & 31723 & 36026 \\
\hline Control group mean & 673.65 & 675.86 & 668.24 & 652.88 & 663.42 & 678.27 \\
\hline \multicolumn{7}{|l|}{ Preterm } \\
\hline Born after Dec. 1991 & $\begin{array}{l}-189.557^{* * *} \\
(59.236)\end{array}$ & $\begin{array}{c}-173.605^{* *} \\
(67.974)\end{array}$ & $\begin{array}{c}-194.42^{* * *} \\
(60.871)\end{array}$ & $\begin{array}{c}-187.337^{* * *} \\
(55.312)\end{array}$ & $\begin{array}{c}-151.467^{* * *} \\
(51.448)\end{array}$ & $\begin{array}{c}-146.563^{* * *} \\
(48.66)\end{array}$ \\
\hline Bandwidth & 1304 & 1000 & 1250 & 1500 & 1750 & 2000 \\
\hline Observations & 25574 & 19589 & 24456 & 29508 & 34390 & 38720 \\
\hline Control group mean & 631.36 & 638.86 & 633.91 & 626.76 & 640.07 & 656.57 \\
\hline \multicolumn{7}{|l|}{$\begin{array}{l}\text { II. Child demographics } \\
\text { Male }\end{array}$} \\
\hline Born after Dec. 1991 & $\begin{array}{l}-15.606^{* * *} \\
(5.798)\end{array}$ & $\begin{array}{l}-13.256 \\
(8.148)\end{array}$ & $\begin{array}{l}-15.198^{* *} \\
(7.318)\end{array}$ & $\begin{array}{l}-17.571^{* * *} \\
(6.623)\end{array}$ & $\begin{array}{c}-17.563^{* * *} \\
(6.138)\end{array}$ & $\begin{array}{c}-15.662^{* * *} \\
(5.803)\end{array}$ \\
\hline Bandwidth & 2002 & 1000 & 1250 & 1500 & 1750 & 2000 \\
\hline Observations & 362347 & 184760 & 229527 & 274521 & 319046 & 361978 \\
\hline Control group mean & 88.23 & 87.05 & 86.62 & 85.47 & 86.49 & 88.2 \\
\hline \multicolumn{7}{|l|}{ First child } \\
\hline Born after Dec. 1991 & $\begin{array}{l}-8.393 \\
(6.033)\end{array}$ & $\begin{array}{r}-12.809 \\
(7.894)\end{array}$ & $\begin{array}{r}-10.221 \\
(7.114)\end{array}$ & $\begin{array}{l}-9.173 \\
(6.466)\end{array}$ & $\begin{array}{l}-8.908 \\
(5.963)\end{array}$ & $\begin{array}{l}-9.584^{*} \\
(5.592)\end{array}$ \\
\hline Bandwidth & 1711 & 1000 & 1250 & 1500 & 1750 & 2000 \\
\hline Observations & 280456 & 166811 & 206880 & 247087 & 286743 & 325152 \\
\hline Control group mean & 71.97 & 70.74 & 71.73 & 71.68 & 72.08 & 73.04 \\
\hline \multicolumn{7}{|c|}{$\begin{array}{l}\text { III. Maternal characteristics } \\
\text { Mother has basic education }\end{array}$} \\
\hline Born after Dec. 1991 & $\begin{array}{l}-15.991^{* *} \\
(7.809)\end{array}$ & $\begin{array}{l}-14.593 \\
(11.819)\end{array}$ & $\begin{array}{l}-20.208^{*} \\
(10.494)\end{array}$ & $\begin{array}{c}-17.998^{*} \\
(9.49)\end{array}$ & $\begin{array}{c}-17.041^{*} \\
(8.744)\end{array}$ & $\begin{array}{l}-11.659 \\
(8.217)\end{array}$ \\
\hline Bandwidth & 2191 & 1000 & 1250 & 1500 & 1750 & 2000 \\
\hline Observations & 239455 & 111241 & 138442 & 165770 & 192850 & 219311 \\
\hline Control group mean & 96.98 & 98.37 & 95.21 & 95.37 & 95.34 & 98.38 \\
\hline \multicolumn{7}{|c|}{ Mother has HS/ voc. education } \\
\hline Born after Dec. 1991 & $\begin{array}{l}-19.481^{* * *} \\
(6.778)\end{array}$ & $\begin{array}{l}-22.338^{* * *} \\
(8.257)\end{array}$ & $\begin{array}{l}-17.906^{* *} \\
(7.471)\end{array}$ & $\begin{array}{l}-19.644^{* * *} \\
(6.771)\end{array}$ & $\begin{array}{l}-17.478^{* * *} \\
(6.252)\end{array}$ & $\begin{array}{c}-20.373^{* * *} \\
(5.875)\end{array}$ \\
\hline Bandwidth & 1478 & 1000 & 1250 & 1500 & 1750 & 2000 \\
\hline Observations & 224073 & 153767 & 190603 & 226870 & 262776 & 296868 \\
\hline Control group mean & 70.85 & 70.48 & 72.2 & 71.03 & 71.61 & 71.06 \\
\hline \multicolumn{7}{|l|}{ Mother has further education } \\
\hline Born after Dec. 1991 & $\begin{array}{l}2.776 \\
(7.879)\end{array}$ & $\begin{array}{l}10.362 \\
(9.316)\end{array}$ & $\begin{array}{l}7.386 \\
(8.39)\end{array}$ & $\begin{array}{c}4.13 \\
(7.602)\end{array}$ & $\begin{array}{l}-1.459 \\
(7.081)\end{array}$ & $\begin{array}{l}-2.343 \\
(6.671)\end{array}$ \\
\hline Bandwidth & 1384 & 1000 & 1250 & 1500 & 1750 & 2000 \\
\hline Observations & 131067 & 94621 & 118068 & 141005 & 164360 & 187045 \\
\hline Control group mean & 57.39 & 55.45 & 57.88 & 58.43 & 59.77 & 60.79 \\
\hline \multicolumn{7}{|l|}{ Mother is an immigrant } \\
\hline Born after Dec. 1991 & $\begin{array}{l}-34.943^{* *} \\
(16.756)\end{array}$ & $\begin{array}{l}-31.622 \\
(20.082)\end{array}$ & $\begin{array}{c}-40.169 * * \\
(17.973)\end{array}$ & $\begin{array}{l}-32.403^{*} \\
(16.557)\end{array}$ & $\begin{array}{l}-26.648^{*} \\
(15.586)\end{array}$ & $\begin{array}{c}-23.792 \\
(14.848)\end{array}$ \\
\hline Bandwidth & 1453 & 1000 & 1250 & 1500 & 1750 & 2000 \\
\hline Observations & 43684 & 30349 & 37715 & 45090 & 52622 & 60301 \\
\hline Control group mean & 81.58 & 95.73 & 86.14 & 81.54 & 80.95 & 81.8 \\
\hline
\end{tabular}

Notes: Table shows the regression discontinuity estimates for the effect of public health information campaign on infant mortality for subgroups. See Appendix Table C1 for the variable definitions. Each column indicates the bandwidth used to restrict the regression sample. Standard errors are clustered at the birthday level and are shown in parentheses. Significance levels are indicated by ${ }^{* * *}<0.01,{ }^{* *}<0.05$, and $*<0.1$. 


\section{Appendix A Additional Material on Home Visiting Program}

\section{A Letter of the Danish National Board of Health}

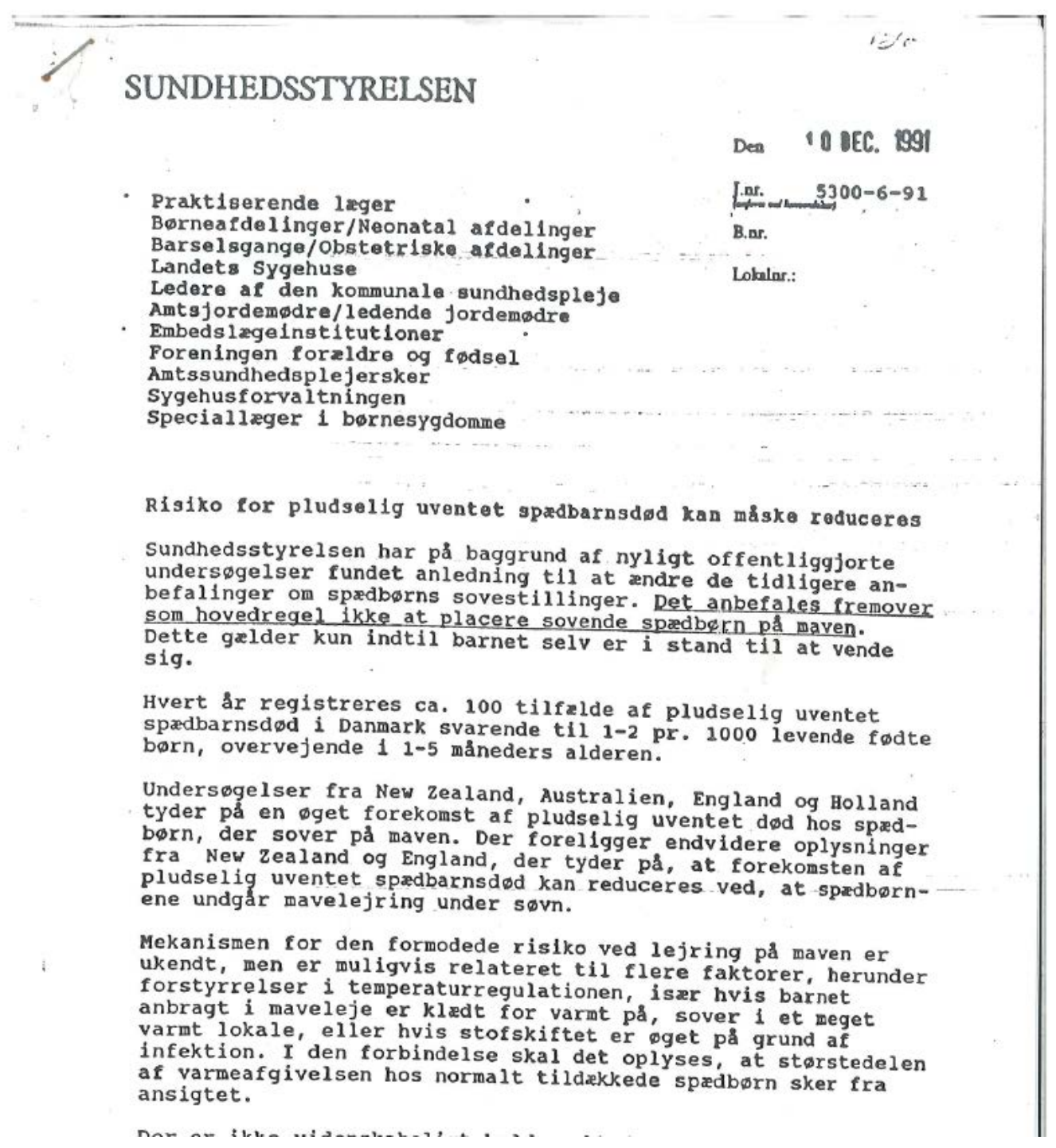

\section{B Danish Home Visiting Program}

The Danish Home Visiting Program was established by the National Board of Health under legislation enacted in 1937. Initially established as a recommended program, the 1937 legislation was later integrated into the Public Health Nursing Services Act in 1963, which stated that municipalities "ought" to establish the service, but still did not make it compulsory (Kamerman and Kahn 1993). By 1962, the program reached almost all newborn children and involved multiple home visits in the first year after birth, with more regular visits in the first few weeks after birth. Although most local jurisdictions adopted the program, it was not until 1973 that it became mandatory, after which time all municipalities had to offer 
visits to new families. ${ }^{16}$ From 1973 through 1995, the organization of the public health nurses was assigned to a leading public health nurse in the region. ${ }^{17}$ According to the guidelines, first-time parents could receive around nine visits between the time of birth and the start of school, while parents with more than one child could receive up to seven visits by a public health nurse, depending on their needs (Danish National Board of Health 1985; Danish Nurses' Organization 2018). The program is universally available to all Danish families with an almost 100-percent take-up rate citephjort2017universal.

At its initial stages, visiting public health nurses routinely collected anthropometric measurements, provided physical examination, and, if necessary, physician referral, and informed parents about the pediatric guidelines on infant nutrition and child care (Matthiessen 1967). Since 1973, the public health nurses have had two key, but distinct roles: (i) to offer care and support to the families and promote health, with a specific focus on breastfeeding (ii) to measure the children and check that the parents follow guidelines and report back to the authorities if they notice any maltreatment (Sixhøj 2001). While it can be difficult to unite these two roles, this problem seems partly to be solved by focusing on health promotion and repeated visits by the same public health nurse to the family, which nurtures a relationship of trust between the families and the public health nurses.

The Home Visiting Program has evolved over time, but its core services remain the same, i.e., informing parents about childcare guidelines, which are routinely updated with new medical evidence. One such important update occurred in December 1991, with a drastic change in the recommended sleeping position for infants from "on the stomach" to "on the back or the side", which was shown in case control studies to be highly effective in mitigating the SIDS risk (Fleming et al. 1990; Mitchell et al. 1991; Ponsonby et al. 1993; Dwyer et al. 1995). Postnatal home visits by public health nurses provided an ideal tool to communicate the updated guidelines due to its capacity to reach all new parents and build a trust-based relationship through repeated visits by the same nurse.

Previous evidence suggests that home visiting programs played an important role in improving infant health such that their impact went beyond early childhood to result in better adult health, education, and earnings (Bhalotra et al. 2017; Bütikofer et al. 2019; Hjort et al. 2017; Moehling and Thomasson 2014; Wüst 2012). While there is consensus on the health benefits of postnatal home visits by public health nurses, the existing studies are limited in explaining which component of these programs (e.g., basic medical services, nutrition advice, or public health information) makes them so valuable. ${ }^{18}$

\footnotetext{
${ }^{16}$ See Lov om Sundhedsplejerske Ordningerne, Lov nr 409 af 13. juni 1973 (n.d.) for the corresponding law article.

${ }^{17}$ At that time there were 14 regions in the country.

${ }^{18}$ For example, Hjort et al. (2017) documents a clear decrease in infant mortality induced by Denmark's Home Visiting Program in 1937, but it is not clear whether the referral of sick children to doctors, hygienic home environments, breastfeeding advice, or a combination of all services drove these changes.
} 
Appendix B Additional Figures 
Figure B1: Balance of Covariates

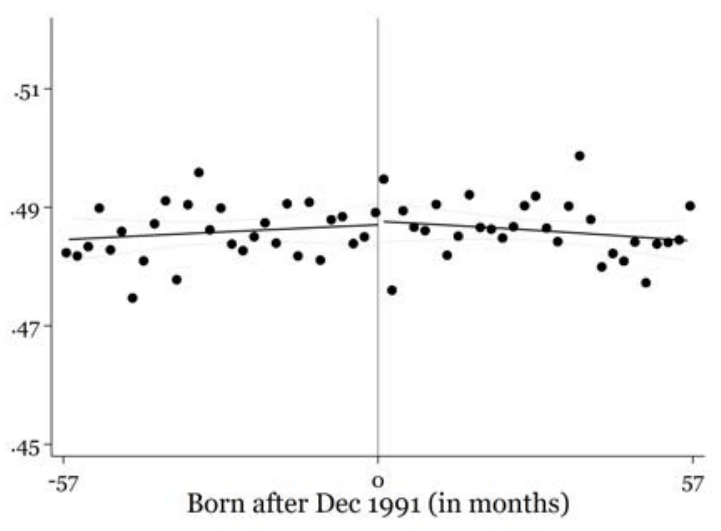

(A) Female

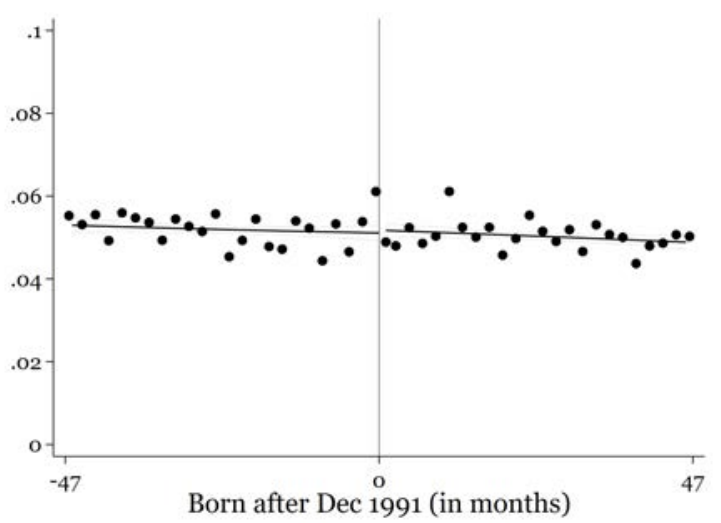

(c) Low birthweight

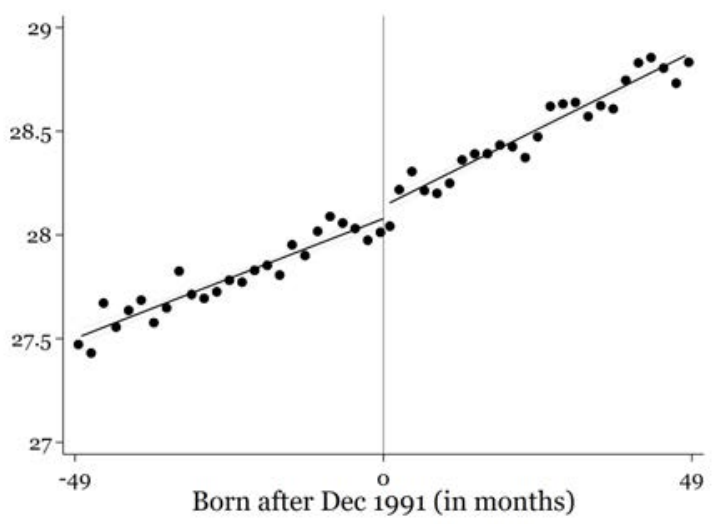

(E) Mother's age at birth

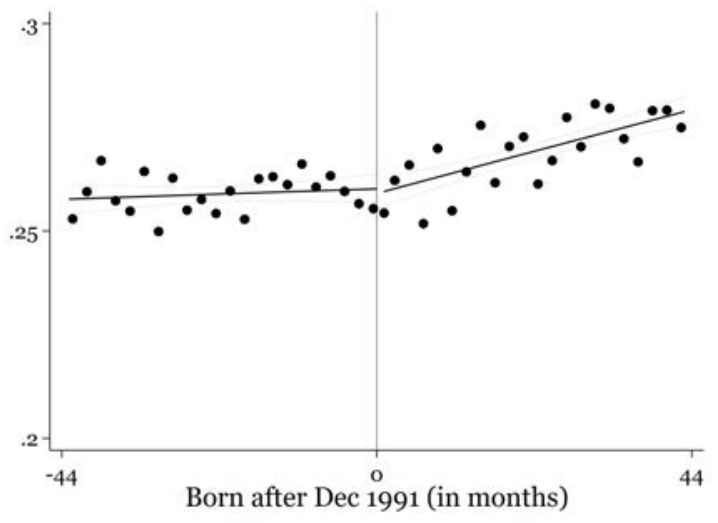

(G) Mother with further education

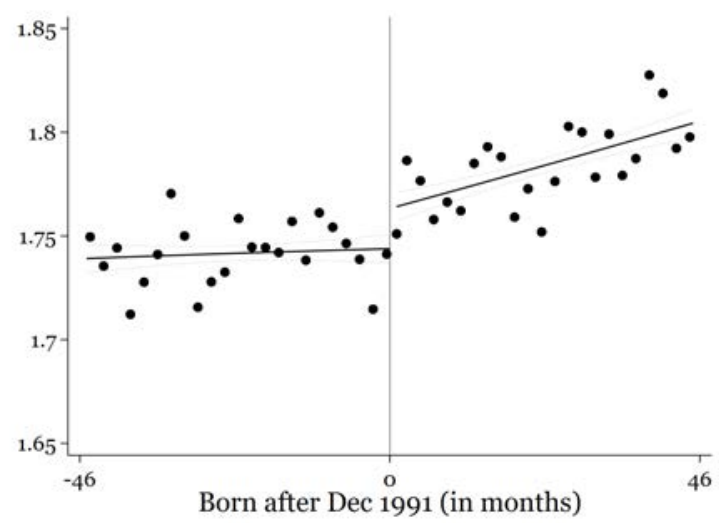

(в) Birth order

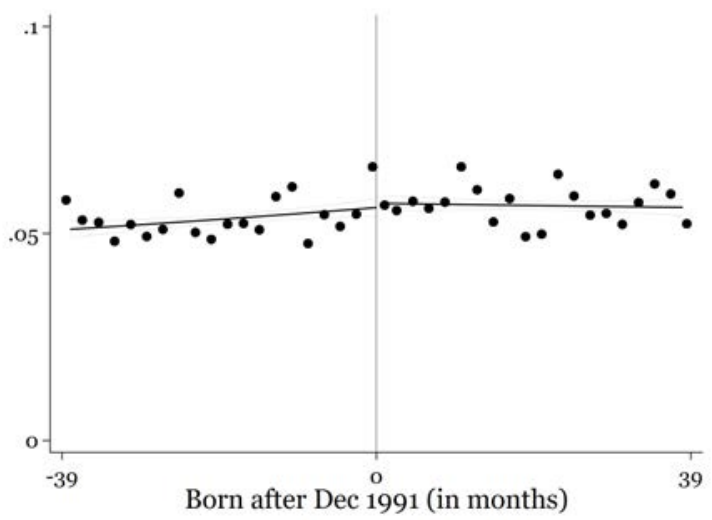

(D) Preterm birth

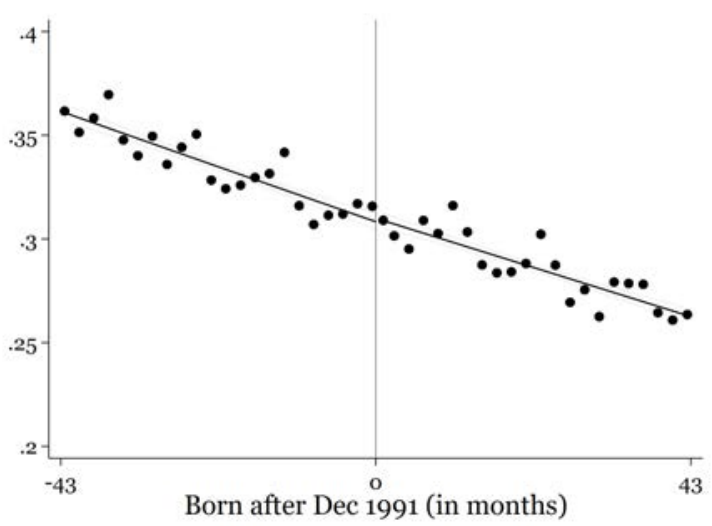

(F) Mother has basic education

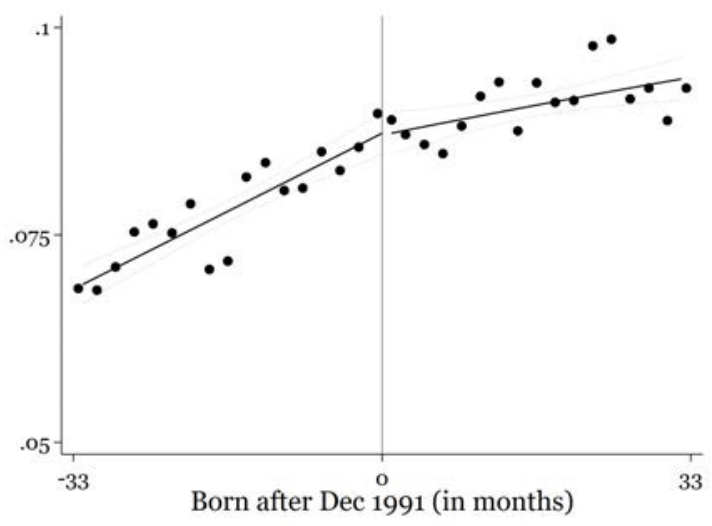

(H) Mother is immigrant 


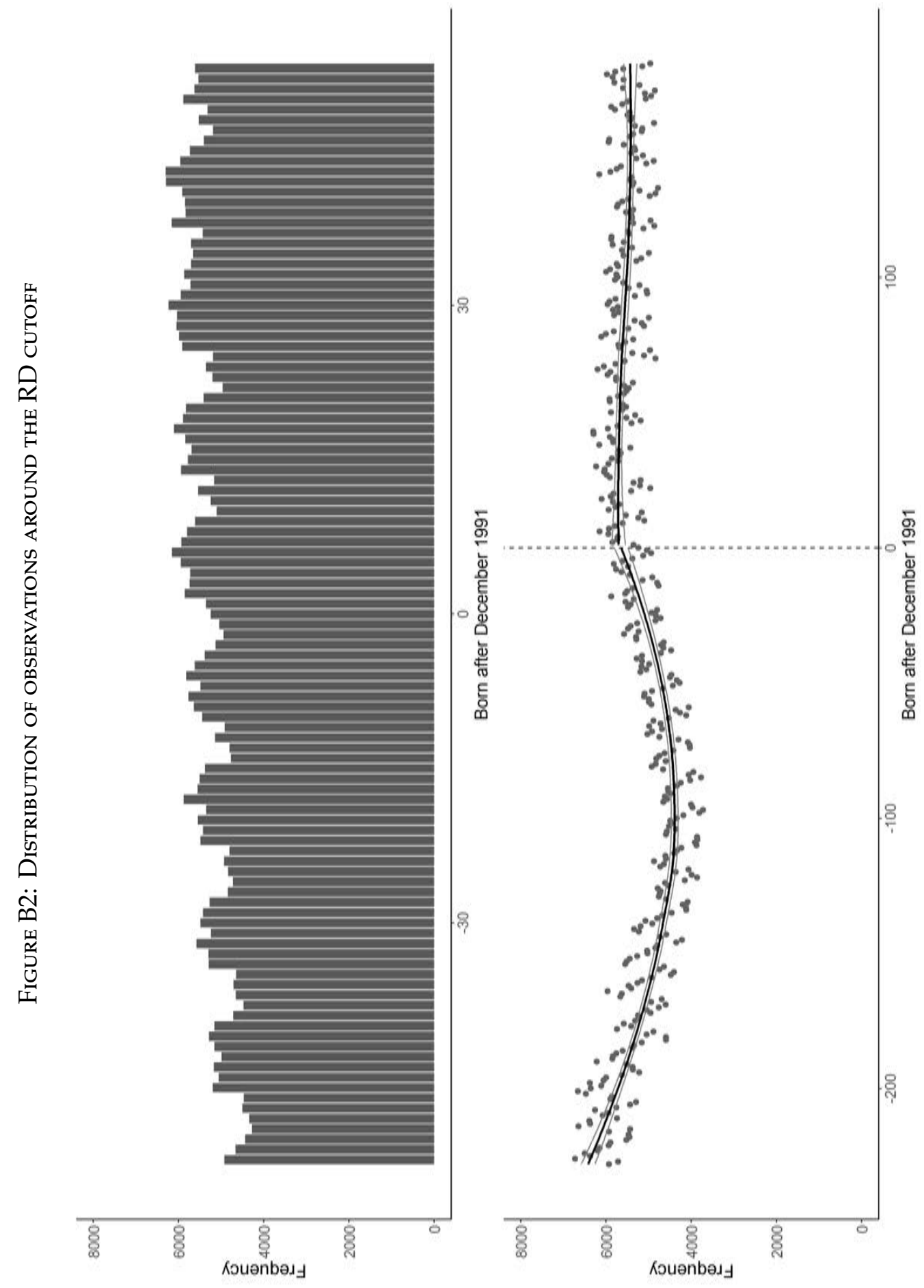


Figure B3: RD estimates on Infant Mortality: Subgroups

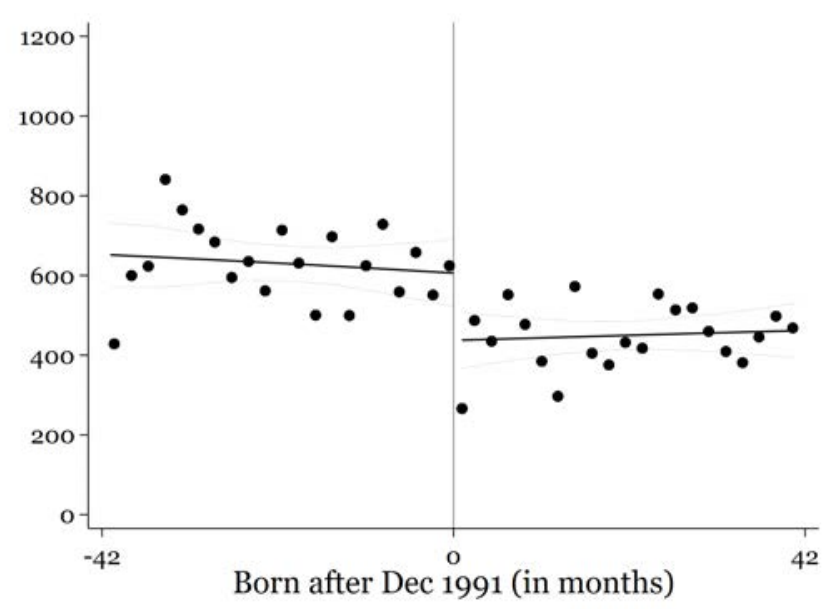

(A) Preterm Birth

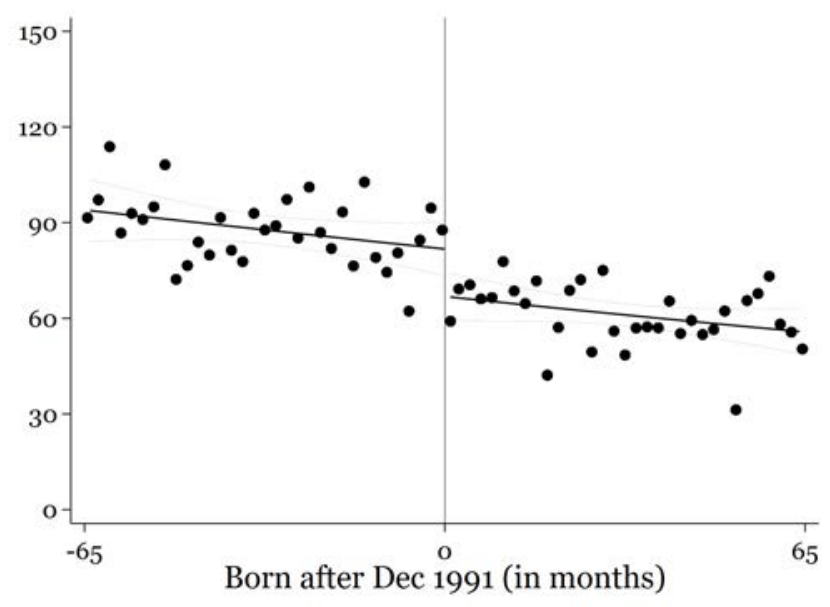

(c) Male

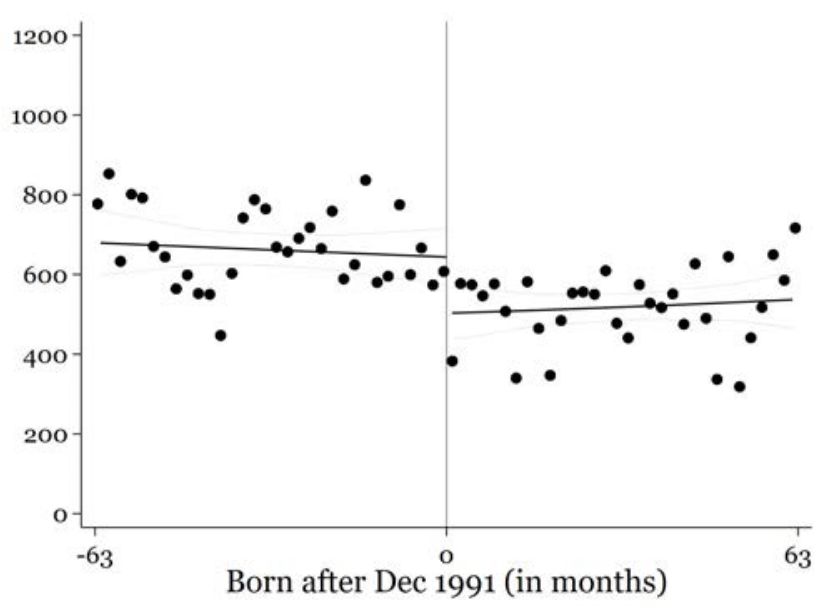

(в) Low Birthweight

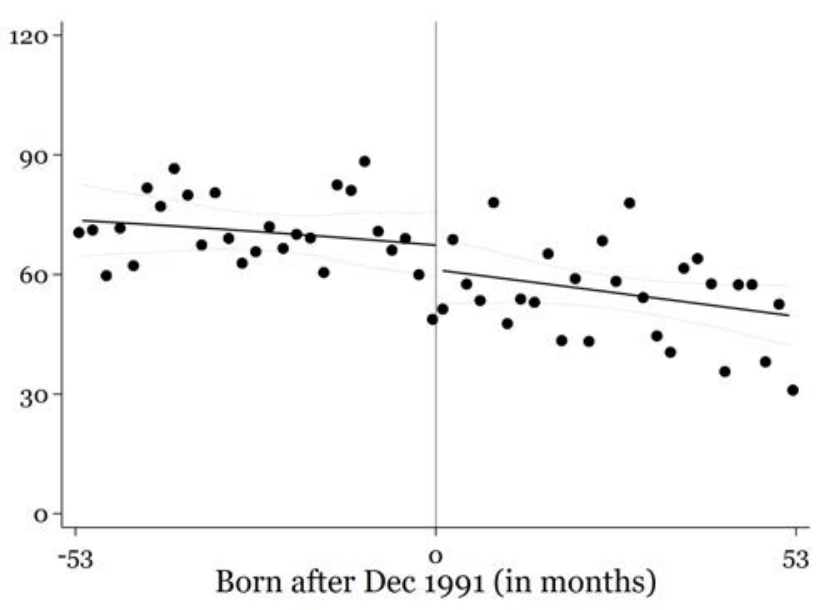

(D) First Child 
Figure B4: RD Estimates on Infant Mortality: Subgroups

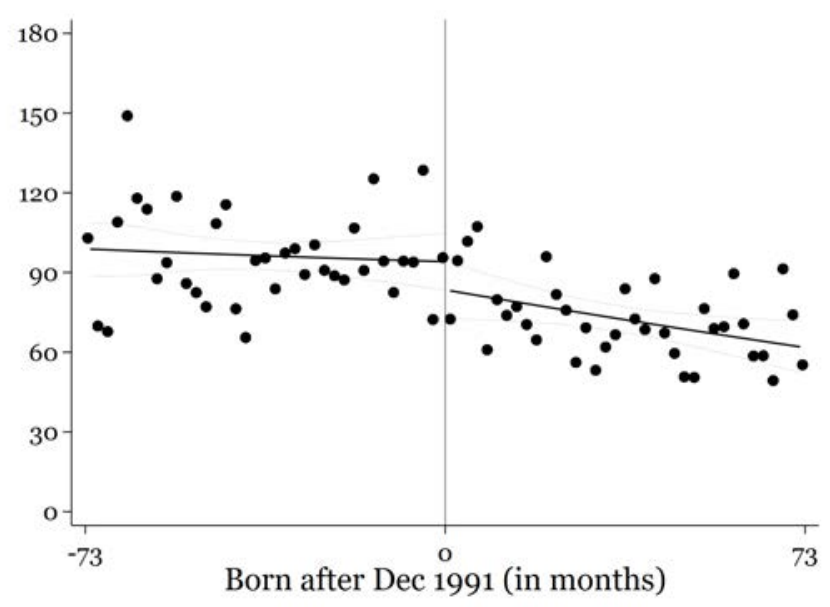

(A) Mother with Basic Education

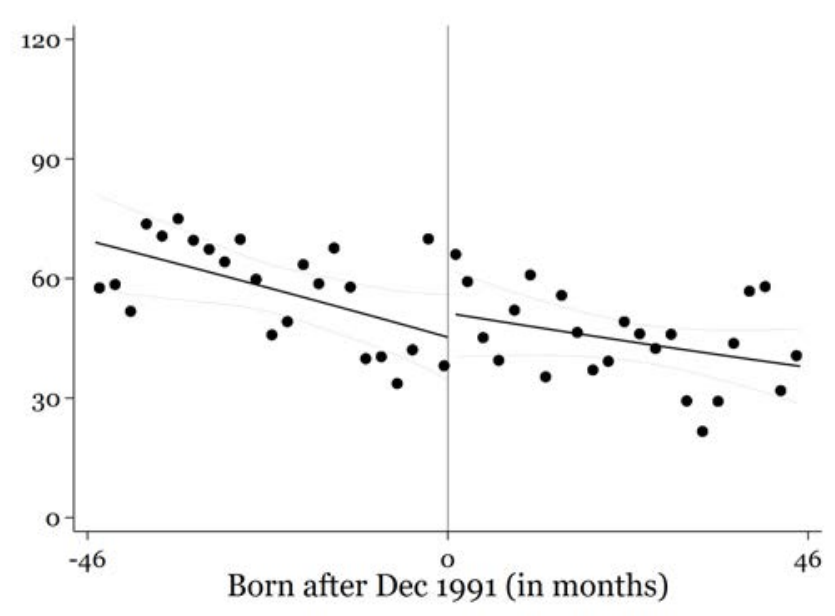

(c) Mother with Further Education

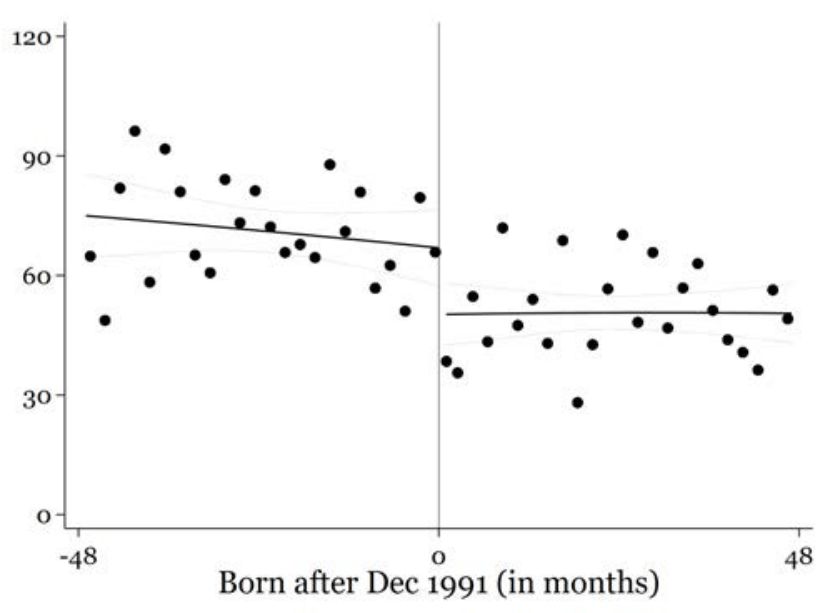

(в) Mother with HS/Voc Education

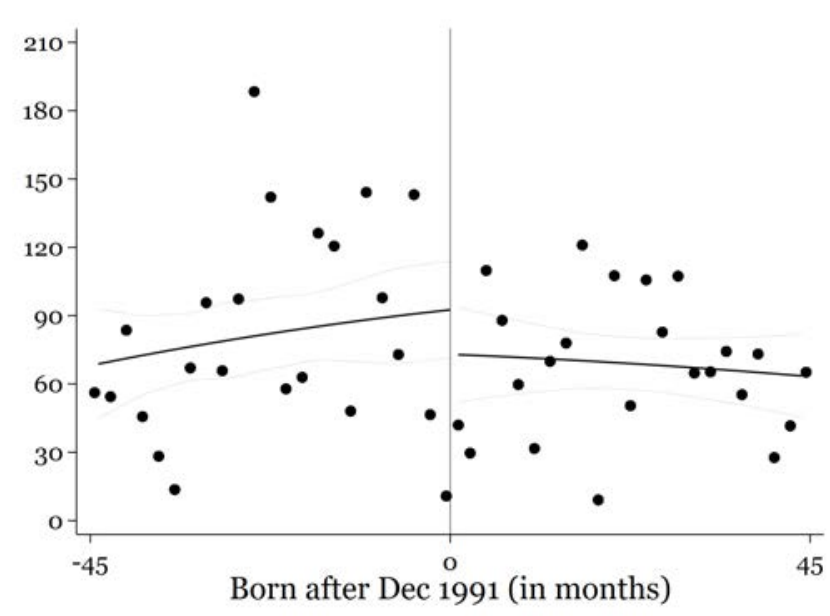

(D) Mother Immigrant 

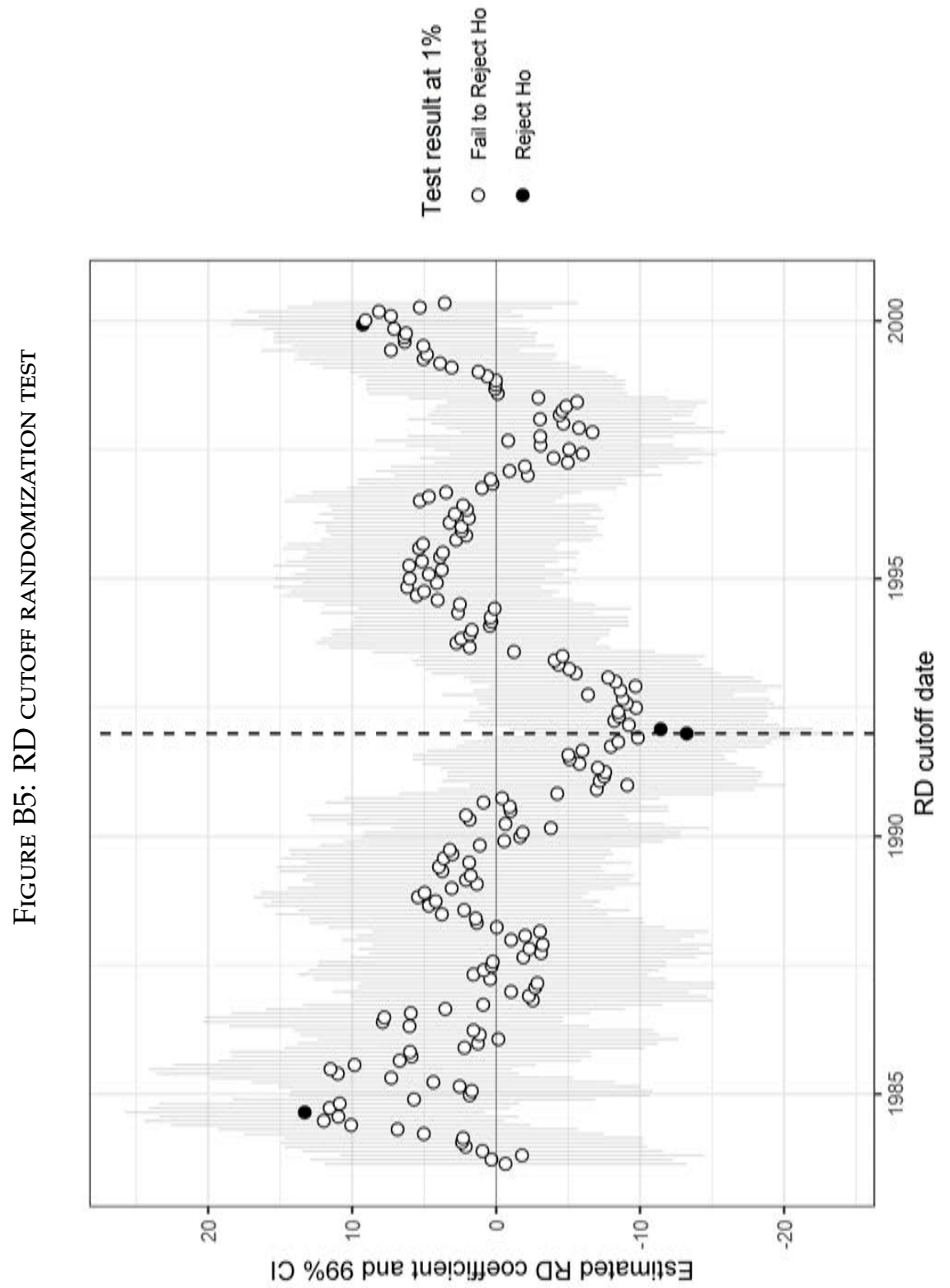


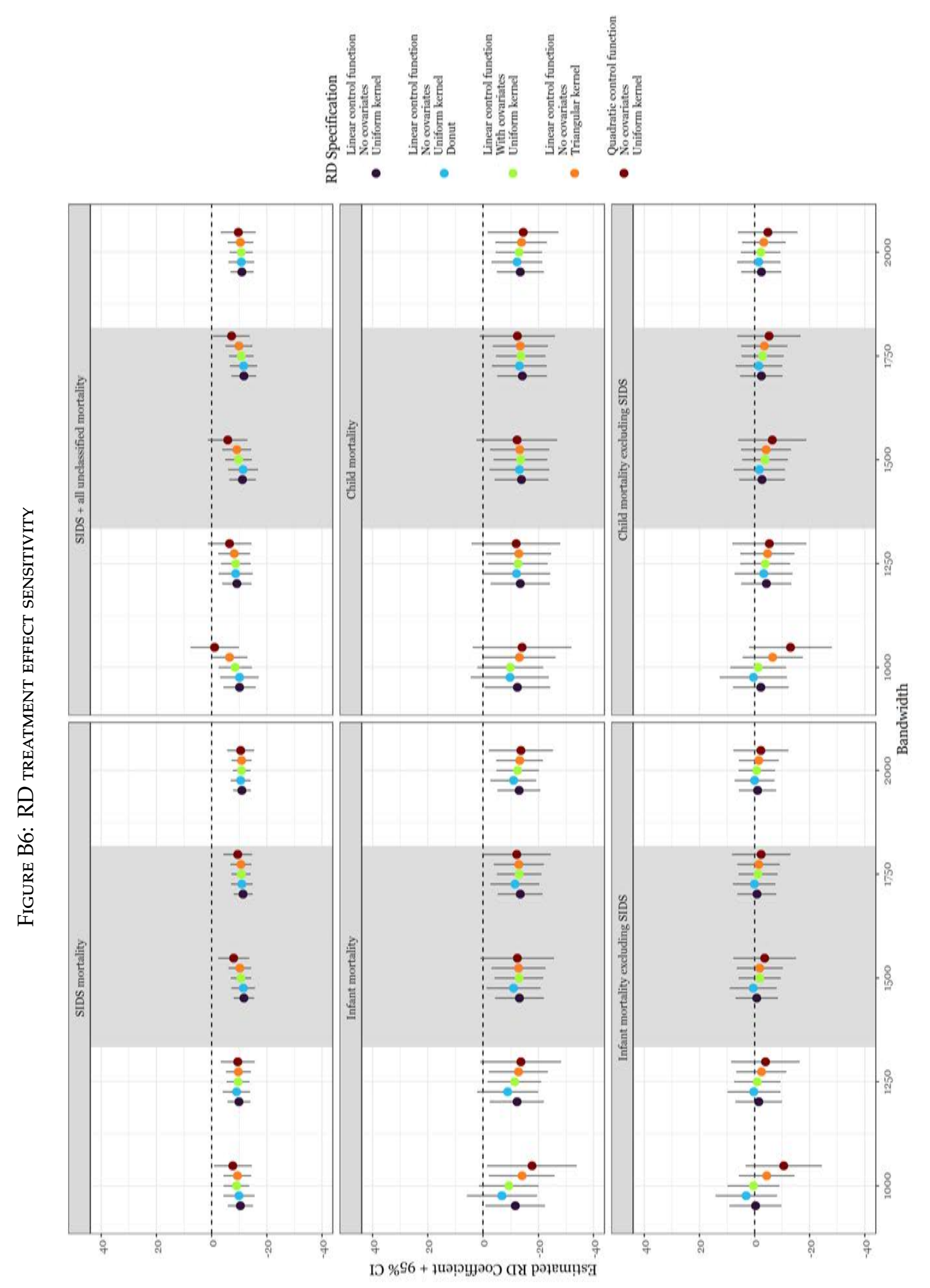


Figure B7: Smoking during the First Trimester of Pregnancy by Birth Cohorts

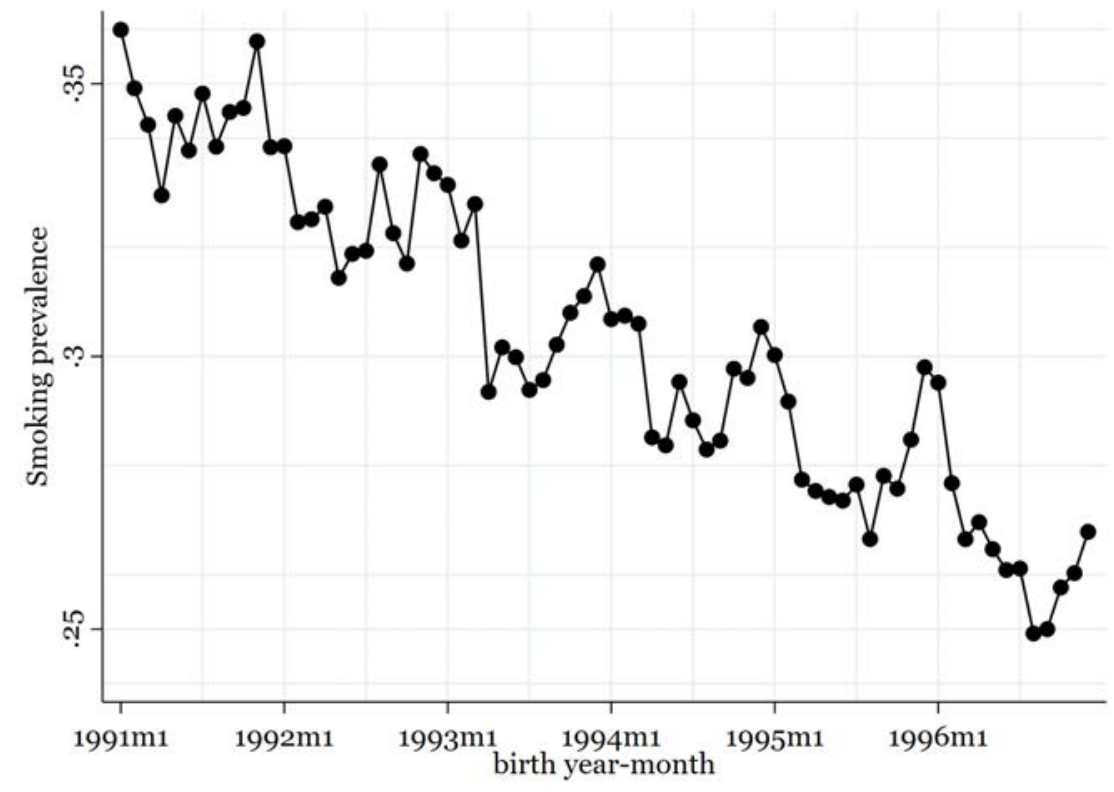


Figure B8: CROSS-COUNTRY COMPARISON OF CHANGES IN INFANT MORTALITY AROUND THE SIDS CAMPAIGNS
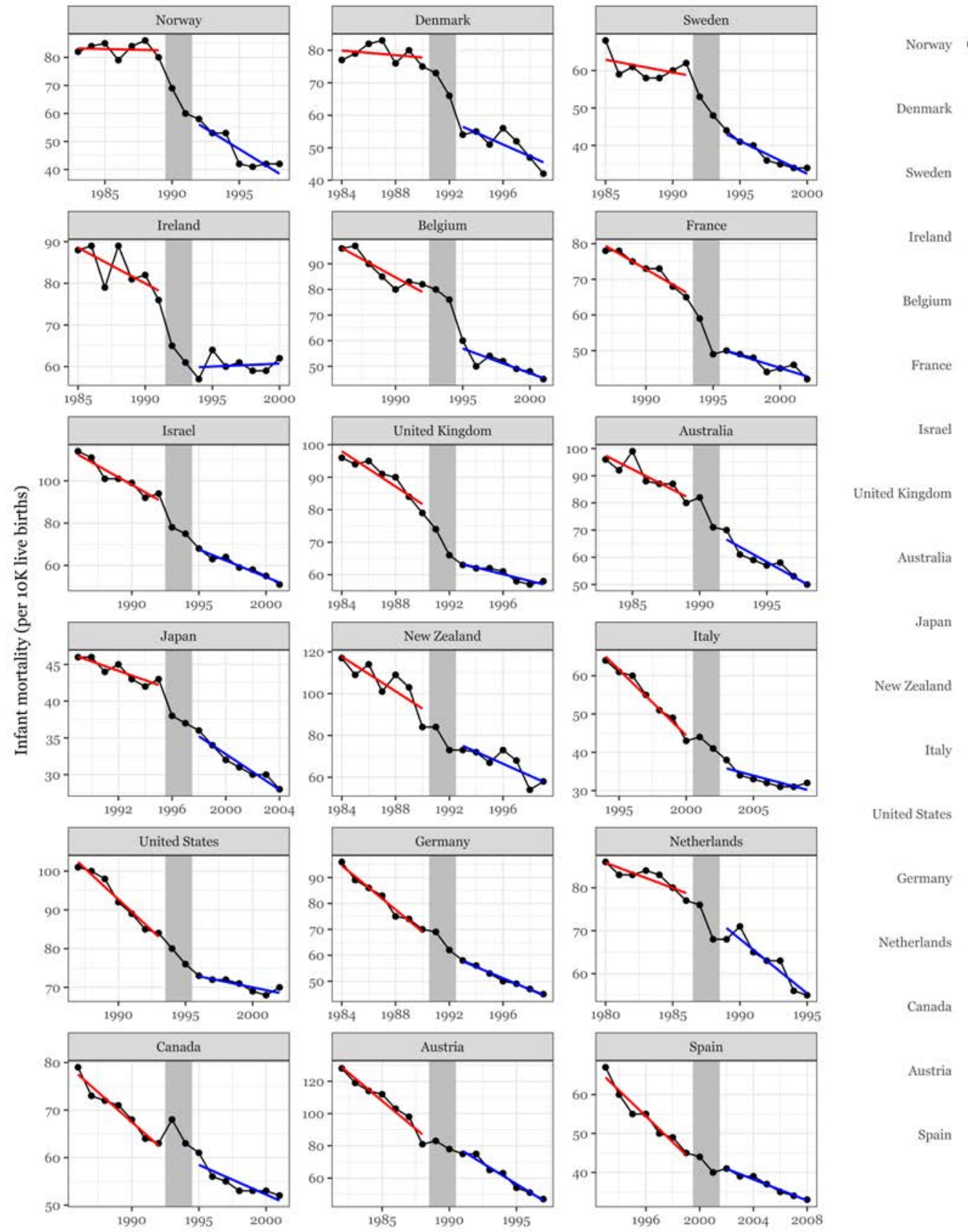


\section{Appendix C Additional Tables}

Table C1: Variable Definitions

\begin{tabular}{|c|c|}
\hline Variable name & Definition \\
\hline Infant mortality & $\begin{array}{l}\text { dummy variable that equals } 1 \text { if the child } \\
\text { is registered in the Danish Death Registry } \\
\text { before reaching age } 1 .\end{array}$ \\
\hline Infant mortality excluding SIDS & $\begin{array}{l}\text { dummy variable that equals } 1 \text { if the child } \\
\text { is registered in the Danish Death Registry } \\
\text { before reaching age } 1 \text { excluding those reg- } \\
\text { istered with the following ICD codes that } \\
\text { indicate the primary cause of death: } 795.0 \\
795.1,795.9 \text { (ICD-8), and R95.0 and R95.9 } \\
\text { (ICD-10). }\end{array}$ \\
\hline $\begin{array}{l}\text { Infant mortality excluding SIDS and all } \\
\text { other unclassified mortality }\end{array}$ & $\begin{array}{l}\text { dummy variables that equal } 1 \text { if the child } \\
\text { is registered in the Danish Death Registry } \\
\text { before reaching age } 1 \text { excluding those reg- } \\
\text { istered with the following ICD codes that } \\
\text { indicate the primary cause of death: } 795.0 \\
795.1,795.9,796.0,796.9 \text { (ICD-8), and R95.0 } \\
\text { R95.9, R96.0, and R99.9 (ICD-10). }\end{array}$ \\
\hline SIDS mortality & $\begin{array}{l}\text { dummy variables that equal } 1 \text { if the child } \\
\text { is registered in the Danish Death Registry } \\
\text { before reaching age } 1 \text { with the following } \\
\text { ICD codes that indicate the primary cause of } \\
\text { death: } 795.0795 .1,795.9 \text { (ICD-8), and R95.0 } \\
\text { and R95.9 (ICD-10). }\end{array}$ \\
\hline Child mortality & $\begin{array}{l}\text { dummy variable that equal } 1 \text { if the child } \\
\text { is registered in the Danish Death Registry } \\
\text { before reaching age } 5 .\end{array}$ \\
\hline Child mortality excluding SIDS & $\begin{array}{l}\text { dummy variable that equal } 1 \text { if the child } \\
\text { is registered in the Danish Death Registry } \\
\text { before reaching age } 5 \text { excluding those reg- } \\
\text { istered with the following ICD codes that } \\
\text { indicate the primary cause of death: } 795.0 \\
795.1,795.9 \text { (ICD-8), and R95.0 and R95.9 } \\
\text { (ICD-10). }\end{array}$ \\
\hline
\end{tabular}




\begin{tabular}{|c|c|}
\hline $\begin{array}{l}\text { Child mortality excluding SIDS and all } \\
\text { other unclassified mortality }\end{array}$ & $\begin{array}{l}\text { dummy variables that equal } 1 \text { if the child } \\
\text { is registered in the Danish Death Registry } \\
\text { before reaching age } 5 \text { excluding those reg- } \\
\text { istered with following ICD codes that indi- } \\
\text { cate the primary cause of death: } 795.0795 .1 \text {, } \\
795.9,796.0,796.9 \text { (ICD-8), and R95.0 R95.9, } \\
\text { R96.0, and R99.9 (ICD-10). }\end{array}$ \\
\hline Female & $\begin{array}{l}\text { Dummy variables that equal } 1 \text { if the child is } \\
\text { female. Information from the Danish med- } \\
\text { ical birth registry. }\end{array}$ \\
\hline Birth order & $\begin{array}{l}\text { Birth order of the child. Information from } \\
\text { the Danish medical birth registry. }\end{array}$ \\
\hline Low birth weight & $\begin{array}{l}\text { dummy variable that equal } 1 \text { if the child is } \\
\text { registered with a birth weight below } 2500 \\
\text { gram in the Danish medical birth registry. }\end{array}$ \\
\hline Preterm birth & $\begin{array}{l}\text { dummy variable that equal } 1 \text { if the child } \\
\text { is registered with a gestational age of less } \\
\text { than } 37 \text { weeks in the Danish medical birth } \\
\text { registry. }\end{array}$ \\
\hline Mother's age at birth & $\begin{array}{l}\text { Mother's age in years at birth. Information } \\
\text { from the Danish medical birth registry. }\end{array}$ \\
\hline Mother immigrant & $\begin{array}{l}\text { dummy variable that equals } 1 \text { if the mother } \\
\text { is first or second generation immigrant. } \\
\text { This group includes both immigrants and } \\
\text { descendants of immigrants. }\end{array}$ \\
\hline Mother's education & $\begin{array}{l}\text { Mother's education is the educational at- } \\
\text { tainment of the mother. The level is cat- } \\
\text { egorized into three groups: Basic educa- } \\
\text { tion includes less than } 12 \text { years of schooling. } \\
\text { Vocational training includes all vocational } \\
\text { training educations and high school. Fur- } \\
\text { ther education includes all short, medium, } \\
\text { and long further education. }\end{array}$ \\
\hline
\end{tabular}


Table C2: Descriptive statistics

\begin{tabular}{lccc}
\hline \hline & Mean & Std. dev. & $N$ \\
\hline Child characteristics & & & \\
Female & 0.49 & 0.5 & 2141226 \\
Birth order & 1.78 & 0.9 & 2143696 \\
Birth weight (in gr) & 3383 & 609 & 2126173 \\
Gestation (weeks) & 39.58 & 1.97 & 1724205 \\
Low birthweight & 0.05 & 0.23 & 2126173 \\
Born preterm & 0.05 & 0.23 & 1724205 \\
& & & \\
Maternal characteristics & & & \\
Age at birth & 27.95 & 4.95 & 2143696 \\
Basic education & 0.33 & 0.47 & 2128679 \\
HS/Vocational education & 0.39 & 0.49 & 2128679 \\
Higher education & 0.27 & 0.45 & 2128679 \\
Immigrant & 0.08 & 0.28 & 2128679 \\
& & & \\
Mortality outcomes & & & \\
SIDS mortality (over 10K) & 7.79 & 279.09 & 2143696 \\
SIDS + unknown mortality (over 10K) & 9.60 & 309.69 & 2143696 \\
Infant mortality (over 10K) & 68.88 & 827.06 & 2143696 \\
Child mortality (over 10K) & 82.52 & 904.66 & 2143696 \\
\hline \hline
\end{tabular}

Notes: Table shows sample descriptive statistics for the variables used in the analysis. See Appendix Table $\mathrm{C} 1$ for the variable definitions. 


\section{Table C3: RD effects on Infant and Child Mortality. With Covariates}

\begin{tabular}{|c|c|c|c|c|c|c|}
\hline & MSE-optimal & \pm 1000 & \pm 1250 & \pm 1500 & \pm 1750 & \pm 2000 \\
\hline \multicolumn{7}{|l|}{ SIDS Mortality } \\
\hline Born after Dec. 1991 & $\begin{array}{c}-11.065^{* * *} \\
(1.864)\end{array}$ & $\begin{array}{c}-8.993^{* * *} \\
(2.359)\end{array}$ & $\begin{array}{c}-9.565^{* * *} \\
(2.129)\end{array}$ & $\begin{array}{c}-10.623^{* * *} \\
(1.9)\end{array}$ & $\begin{array}{c}-10.699^{* * *} \\
(1.763)\end{array}$ & $\begin{array}{c}-10.887^{* * *} \\
(1.66)\end{array}$ \\
\hline Bandwidth & 1554 & 1000 & 1250 & 1500 & 1750 & 2000 \\
\hline Observations & 553020 & 360502 & 448200 & 535007 & 621589 & 705141 \\
\hline Control group mean & 17.72 & 17.89 & 18.33 & 17.71 & 18.04 & 18.17 \\
\hline \multicolumn{7}{|c|}{ SIDS + All Unclassified Mortality } \\
\hline Born after Dec. 1991 & $\begin{array}{c}-9.177^{* * *} \\
(2.632)\end{array}$ & $\begin{array}{c}-8.553^{* * *} \\
(3.051)\end{array}$ & $\begin{array}{c}-8.755^{* * *} \\
(2.742)\end{array}$ & $\begin{array}{c}-9.761^{* * *} \\
(2.466)\end{array}$ & $\begin{array}{c}-10.744^{* * *} \\
(2.287)\end{array}$ & $\begin{array}{c}-10.713^{* * *} \\
(2.16)\end{array}$ \\
\hline Bandwidth & 1334 & 1000 & 1250 & 1500 & 1750 & 2000 \\
\hline Observations & 479110 & 360502 & 448200 & 535007 & 621589 & 705141 \\
\hline Control group mean & 27.13 & 26.64 & 27.26 & 26.54 & 27.04 & 27.41 \\
\hline \multicolumn{7}{|l|}{ Infant mortality } \\
\hline Born after Dec. 1991 & $\begin{array}{c}-12.615^{* * *} \\
(4.077)\end{array}$ & $\begin{array}{l}-9.301^{*} \\
(5.497)\end{array}$ & $\begin{array}{c}-11.376^{* *} \\
(4.937)\end{array}$ & $\begin{array}{c}-12.981^{* * *} \\
(4.479)\end{array}$ & $\begin{array}{c}-13.05^{* * *} \\
(4.103)\end{array}$ & $\begin{array}{c}-12.511^{* * *} \\
(3.872)\end{array}$ \\
\hline Bandwidth & 1799 & 1000 & 1250 & 1500 & 1750 & 2000 \\
\hline Observations & 637804 & 360502 & 448200 & 535007 & 621589 & 705141 \\
\hline Control group mean & 76.82 & 75.61 & 76.21 & 76.04 & 76.72 & 77.98 \\
\hline \multicolumn{7}{|l|}{ Child Mortality } \\
\hline Born after Dec. 1991 & $\begin{array}{c}-13.901^{* * *} \\
(4.513)\end{array}$ & $\begin{array}{l}-9.864 \\
(6.071)\end{array}$ & $\begin{array}{c}-12.636^{* *} \\
(5.452)\end{array}$ & $\begin{array}{c}-13.544^{* * *} \\
(4.952)\end{array}$ & $\begin{array}{c}-13.643^{* * *} \\
(4.563)\end{array}$ & $\begin{array}{c}-12.97^{* * *} \\
(4.276)\end{array}$ \\
\hline Bandwidth & 1818 & 1000 & 1250 & 1500 & 1750 & 2000 \\
\hline Observations & 643921 & 360502 & 448200 & 535007 & 621589 & 705141 \\
\hline Control group mean & 91.37 & 89.36 & 89.77 & 89.81 & 91.18 & 92.54 \\
\hline \multicolumn{7}{|c|}{ Infant mortality excluding SIDS } \\
\hline Born after Dec. 1991 & $\begin{array}{l}-2.134 \\
(3.859)\end{array}$ & $\begin{array}{c}0.352 \\
(4.796)\end{array}$ & $\begin{array}{l}-0.965 \\
(4.294)\end{array}$ & $\begin{array}{l}-1.855 \\
(3.933)\end{array}$ & $\begin{array}{l}-1.252 \\
(3.611)\end{array}$ & $\begin{array}{l}-0.803 \\
(3.397)\end{array}$ \\
\hline Bandwidth & 1533 & 1000 & 1250 & 1500 & 1750 & 2000 \\
\hline Observations & 545897 & 360502 & 448200 & 535007 & 621589 & 705141 \\
\hline Control group mean & 54.94 & 54.2 & 54.42 & 54.94 & 55.41 & 56.36 \\
\hline \multicolumn{7}{|c|}{ Child mortality excluding SIDS } \\
\hline Born after Dec. 1991 & $\begin{array}{l}-4.011 \\
(4.367)\end{array}$ & $\begin{array}{l}-1.311 \\
(5.173)\end{array}$ & $\begin{array}{l}-3.881 \\
(4.63)\end{array}$ & $\begin{array}{l}-3.783 \\
(4.243)\end{array}$ & $\begin{array}{l}-2.899 \\
(3.917)\end{array}$ & $\begin{array}{l}-2.257 \\
(3.665)\end{array}$ \\
\hline Bandwidth & 1423 & 1000 & 1250 & 1500 & 1750 & 2000 \\
\hline Observations & 510634 & 360502 & 448200 & 535007 & 621589 & 705141 \\
\hline Control group mean & 63.17 & 62.72 & 62.51 & 63.26 & 64.14 & 65.14 \\
\hline
\end{tabular}

Notes: Table shows the regression discontinuity estimates for the effect of public health information campaign on infant and child mortality after controlling for mother's age at birth, gender, month of birth, and birth order fixed-effects, dummy variables for low birthweight and preterm birth, mother's education category and immigrant status. See Appendix Table C1 for the variable definitions. Each column indicates the bandwidth used to restrict the regression sample. Standard errors are clustered at the birthday level, and are shown in parentheses. Significance levels are indicated by ${ }^{* * *}<0.01,{ }^{* *}<0.05$, and ${ }^{*}<0.1$. 


\section{Table C4: RD efFects on Infant and Child Mortality. Donut RD}

\begin{tabular}{|c|c|c|c|c|c|c|}
\hline & MSE-optimal & \pm 100 & \pm 1250 & \pm 1500 & \pm 1750 & \pm 2000 \\
\hline \multicolumn{7}{|l|}{ SIDS Mortality } \\
\hline Born after Dec. 1991 & $\begin{array}{c}-11.378^{* * *} \\
(2.152)\end{array}$ & $\begin{array}{c}-9.861^{* * *} \\
(2.885)\end{array}$ & $\begin{array}{c}-9.003^{* * *} \\
(2.524)\end{array}$ & $\begin{array}{c}-11.465^{* * *} \\
(2.201)\end{array}$ & $\begin{array}{c}-10.973^{* * *} \\
(2.01)\end{array}$ & $\begin{array}{c}-10.525^{* * *} \\
(1.858)\end{array}$ \\
\hline Bandwidth & 1554 & 1000 & 1250 & 1500 & 1750 & 2000 \\
\hline Observations & 532512 & 339994 & 427692 & 514499 & 601081 & 684633 \\
\hline Control group mean & 17.56 & 17.68 & 18.2 & 17.55 & 17.93 & 18.08 \\
\hline \multicolumn{7}{|c|}{ SIDS + All Unclassified Mortality } \\
\hline Born after Dec. 1991 & $\begin{array}{c}-9.633^{* * *} \\
(2.999)\end{array}$ & $\begin{array}{c}-10.084^{* * *} \\
(3.572)\end{array}$ & $\begin{array}{c}-8.713^{* * *} \\
(3.148)\end{array}$ & $\begin{array}{c}-11.412^{* * *} \\
(2.784)\end{array}$ & $\begin{array}{c}-11.555^{* * *} \\
(2.546)\end{array}$ & $\begin{array}{c}-10.757^{* * *} \\
(2.381)\end{array}$ \\
\hline Bandwidth & 1334 & 1000 & 1250 & 1500 & 1750 & 2000 \\
\hline Observations & 458602 & 339994 & 427692 & 514499 & 601081 & 684633 \\
\hline Control group mean & 27.16 & 26.62 & 27.3 & 26.52 & 27.06 & 27.44 \\
\hline \multicolumn{7}{|l|}{ Infant mortality } \\
\hline Born after Dec. 1991 & $\begin{array}{c}-11.383^{* *} \\
(4.459)\end{array}$ & $\begin{array}{c}-6.85 \\
(6.476)\end{array}$ & $\begin{array}{l}-8.895 \\
(5.636)\end{array}$ & $\begin{array}{c}-11.015^{* *} \\
(4.963)\end{array}$ & $\begin{array}{c}-11.559^{* *} \\
(4.51)\end{array}$ & $\begin{array}{c}-10.952^{* * * *} \\
(4.227)\end{array}$ \\
\hline Bandwidth & 1799 & 1000 & 1250 & 1500 & 1750 & 2000 \\
\hline Observations & 617296 & 339994 & 427692 & 514499 & 601081 & 684633 \\
\hline Control group mean & 76.66 & 75.15 & 75.91 & 75.78 & 76.55 & 77.91 \\
\hline \multicolumn{7}{|l|}{ Child Mortality } \\
\hline Born after Dec. 1991 & $\begin{array}{c}-13.907^{* * *} \\
(4.93)\end{array}$ & $\begin{array}{l}-9.687 \\
(7.188)\end{array}$ & $\begin{array}{c}-12.013^{*} \\
(6.246)\end{array}$ & $\begin{array}{c}-13.168^{* *} \\
(5.513)\end{array}$ & $\begin{array}{c}-13.128^{* * * *} \\
(5.035)\end{array}$ & $\begin{array}{c}-12.269^{* * * *} \\
(4.685)\end{array}$ \\
\hline Bandwidth & 1818 & 1000 & 1250 & 1500 & 1750 & 2000 \\
\hline Observations & 623413 & 339994 & 427692 & 514499 & 601081 & 684633 \\
\hline Control group mean & 91.56 & 89.44 & 89.87 & 89.9 & 91.36 & 92.8 \\
\hline \multicolumn{7}{|c|}{ Infant mortality excluding SIDS } \\
\hline Born after Dec. 1991 & $\begin{array}{c}0.291 \\
(4.3)\end{array}$ & $\begin{array}{c}2.993 \\
(5.698)\end{array}$ & $\begin{array}{c}0.252 \\
(4.911)\end{array}$ & $\begin{array}{c}0.519 \\
(4.353)\end{array}$ & $\begin{array}{c}0.105 \\
(3.964)\end{array}$ & $\begin{array}{c}-0.03 \\
(3.707)\end{array}$ \\
\hline Bandwidth & 1533 & 1000 & 1250 & 1500 & 1750 & 2000 \\
\hline Observations & 525389 & 339994 & 427692 & 514499 & 601081 & 684633 \\
\hline Control group mean & 55.01 & 54.21 & 54.45 & 55.01 & 55.5 & 56.5 \\
\hline \multicolumn{7}{|c|}{ Child mortality excluding SIDS } \\
\hline Born after Dec. 1991 & $\begin{array}{r}-1.725 \\
(4.88)\end{array}$ & $\begin{array}{c}0.397 \\
(6.221)\end{array}$ & $\begin{array}{c}-3.3 \\
(5.342)\end{array}$ & $\begin{array}{l}-1.756 \\
(4.735)\end{array}$ & $\begin{array}{l}-1.573 \\
(4.329)\end{array}$ & $\begin{array}{l}-1.512 \\
(4.024)\end{array}$ \\
\hline Bandwidth & 1423 & 1000 & 1250 & 1500 & 1750 & 2000 \\
\hline Observations & 490126 & 339994 & 427692 & 514499 & 601081 & 684633 \\
\hline Control group mean & 63.28 & 62.82 & 62.57 & 63.38 & 64.3 & 65.35 \\
\hline
\end{tabular}

Notes: Table shows the regression discontinuity estimates for the effect of public health information campaign on infant and child mortality. Effect sizes and outcome means are expressed per 10 thousand live births. See Appendix Table C1 for the variable definitions. Each column indicates the bandwidth used to restrict the regression sample. Standard errors are clustered at the birthday level, and are shown in parentheses. Significance levels are indicated by $* * * 0.01,{ }^{* *}<0.05$, and ${ }^{*}<0.1$. 


\section{Table C5: RD effects on Infant and Child Mortality: Triangular Kernel}

\begin{tabular}{|c|c|c|c|c|c|c|}
\hline & MSE-optimal & \pm 1000 & \pm 1250 & \pm 1500 & \pm 1750 & \pm 2000 \\
\hline \multicolumn{7}{|l|}{ SIDS Mortality } \\
\hline Born after Dec. 1991 & $\begin{array}{c}-10.404^{* * *} \\
(2.081)\end{array}$ & $\begin{array}{c}-9.334^{* * *} \\
(2.577)\end{array}$ & $\begin{array}{c}-9.73^{* * *} \\
(2.31)\end{array}$ & $\begin{array}{c}-10.263^{* * *} \\
(2.116)\end{array}$ & $\begin{array}{c}-10.645^{* * *} \\
(1.965)\end{array}$ & $\begin{array}{c}-10.822^{* * *} \\
(1.842)\end{array}$ \\
\hline Bandwidth & 1554 & 1000 & 1250 & 1500 & 1750 & 2000 \\
\hline Observations & 552601 & 360126 & 447840 & 534685 & 621232 & 704791 \\
\hline Control group mean & 17.73 & 17.91 & 18.3 & 17.68 & 18.01 & 18.18 \\
\hline \multicolumn{7}{|c|}{ SIDS + All Unclassified Mortality } \\
\hline Born after Dec. 1991 & $\begin{array}{c}-8.374^{* * *} \\
(2.859)\end{array}$ & $\begin{array}{l}-6.523^{* *} \\
(3.287)\end{array}$ & $\begin{array}{c}-8.143^{* * *} \\
(2.95)\end{array}$ & $\begin{array}{c}-9.108^{* * *} \\
(2.702)\end{array}$ & $\begin{array}{c}-9.879 * * * \\
(2.512)\end{array}$ & $\begin{array}{c}-10.45^{* * *} \\
(2.356)\end{array}$ \\
\hline Bandwidth & 1334 & 1000 & 1250 & 1500 & 1750 & 2000 \\
\hline Observations & 478769 & 360126 & 447840 & 534685 & 621232 & 704791 \\
\hline Control group mean & 27.1 & 26.67 & 27.23 & 26.52 & 27.02 & 27.42 \\
\hline \multicolumn{7}{|l|}{ Infant mortality } \\
\hline Born after Dec. 1991 & $\begin{array}{c}-12.993^{* * *} \\
(4.536)\end{array}$ & $\begin{array}{c}-14.06^{* *} \\
(6.062)\end{array}$ & $\begin{array}{c}-12.778^{* *} \\
(5.435)\end{array}$ & $\begin{array}{c}-12.853^{* * *} \\
(4.965)\end{array}$ & $\begin{array}{c}-12.945^{* * *} \\
(4.6)\end{array}$ & $\begin{array}{c}-13.255^{* * *} \\
(4.302)\end{array}$ \\
\hline Bandwidth & 1799 & 1000 & 1250 & 1500 & 1750 & 2000 \\
\hline Observations & 637463 & 360126 & 447840 & 534685 & 621232 & 704791 \\
\hline Control group mean & 76.69 & 75.68 & 76.18 & 76 & 76.63 & 78.02 \\
\hline \multicolumn{7}{|l|}{ Child Mortality } \\
\hline Born after Dec. 1991 & $\begin{array}{c}-13.533^{* * *} \\
(4.982)\end{array}$ & $\begin{array}{c}-13.094^{* *} \\
(6.672)\end{array}$ & $\begin{array}{c}-12.856^{* *} \\
(5.987)\end{array}$ & $\begin{array}{c}-13.272^{* *} \\
(5.475)\end{array}$ & $\begin{array}{c}-13.446^{* * *} \\
(5.078)\end{array}$ & $\begin{array}{c}-13.852^{* * *} \\
(4.753)\end{array}$ \\
\hline Bandwidth & 1818 & 1000 & 1250 & 1500 & 1750 & 2000 \\
\hline Observations & 643632 & 360126 & 447840 & 534685 & 621232 & 704791 \\
\hline Control group mean & 91.38 & 89.45 & 89.75 & 89.77 & 91.09 & 92.59 \\
\hline \multicolumn{7}{|c|}{ Infant mortality excluding SIDS } \\
\hline Born after Dec. 1991 & $\begin{array}{l}-1.847 \\
(4.22)\end{array}$ & $\begin{array}{c}-4.421 \\
(5.149)\end{array}$ & $\begin{array}{l}-2.465 \\
(4.648)\end{array}$ & $\begin{array}{l}-1.913 \\
(4.263)\end{array}$ & $\begin{array}{l}-1.494 \\
(3.964)\end{array}$ & $\begin{array}{c}-1.542 \\
(3.718)\end{array}$ \\
\hline Bandwidth & 1533 & 1000 & 1250 & 1500 & 1750 & 2000 \\
\hline Observations & 545545 & 360126 & 447840 & 534685 & 621232 & 704791 \\
\hline Control group mean & 54.94 & 54.26 & 54.42 & 54.92 & 55.34 & 56.38 \\
\hline \multicolumn{7}{|c|}{ Child mortality excluding SIDS } \\
\hline Born after Dec. 1991 & $\begin{array}{l}-4.434 \\
(4.734)\end{array}$ & $\begin{array}{l}-6.571 \\
(5.58)\end{array}$ & $\begin{array}{l}-4.714 \\
(5.035)\end{array}$ & $\begin{array}{c}-4.164 \\
(4.618)\end{array}$ & $\begin{array}{l}-3.567 \\
(4.295)\end{array}$ & $\begin{array}{l}-3.402 \\
(4.03)\end{array}$ \\
\hline Bandwidth & 1423 & 1000 & 1250 & 1500 & 1750 & 2000 \\
\hline Observations & 510297 & 360126 & 447840 & 534685 & 621232 & 704791 \\
\hline Control group mean & 63.12 & 62.78 & 62.52 & 63.25 & 64.07 & 65.17 \\
\hline
\end{tabular}

Notes: Table shows the regression discontinuity estimates for the effect of public health information campaign on infant and child mortality using a triangle kernel to weight the regression sample. See Appendix Table C1 for the variable definitions. Each column indicates the bandwidth used to restrict the regression sample. Standard errors are clustered at the month-year cohort level and are shown in parentheses. Significance levels are indicated by $* * *<$ $0.01, * *<0.05$, and $*<0.1$. 
Table C6: RD Effects on Infant and Child Mortaltty: Quadratic Control Function

\begin{tabular}{|c|c|c|c|c|c|c|}
\hline & MSE-optimal & \pm 1000 & \pm 1250 & \pm 1500 & \pm 1750 & \pm 2000 \\
\hline \multicolumn{7}{|l|}{ SIDS Mortality } \\
\hline Born after Dec. 1991 & $\begin{array}{c}-8.462^{* * *} \\
(2.811)\end{array}$ & $\begin{array}{c}-7.714^{* *} \\
(3.521)\end{array}$ & $\begin{array}{c}-9.513^{* * *} \\
(3.153)\end{array}$ & $\begin{array}{c}-7.992^{* * *} \\
(2.858)\end{array}$ & $\begin{array}{c}-9.461^{* * *} \\
(2.661)\end{array}$ & $\begin{array}{c}-10.576^{* * *} \\
(2.497)\end{array}$ \\
\hline Bandwidth & 1554 & 1000 & 1250 & 1500 & 1750 & 2000 \\
\hline Observations & 553020 & 360502 & 448200 & 535007 & 621589 & 705141 \\
\hline Control group mean & 17.72 & 17.89 & 18.33 & 17.71 & 18.04 & 18.17 \\
\hline \multicolumn{7}{|c|}{ SIDS + All Unclassified Mortality } \\
\hline Born after Dec. 1991 & $\begin{array}{l}-6.092 \\
(3.886)\end{array}$ & $\begin{array}{l}-1.095 \\
(4.469)\end{array}$ & $\begin{array}{l}-6.541 \\
(4.028)\end{array}$ & $\begin{array}{l}-5.836 \\
(3.67)\end{array}$ & $\begin{array}{c}-7.185^{* *} \\
(3.41)\end{array}$ & $\begin{array}{c}-9.636^{* * *} \\
(3.221)\end{array}$ \\
\hline Bandwidth & 1334 & 1000 & 1250 & 1500 & 1750 & 2000 \\
\hline Observations & 479110 & 360502 & 448200 & 535007 & 621589 & 705141 \\
\hline Control group mean & 27.13 & 26.64 & 27.26 & 26.54 & 27.04 & 27.41 \\
\hline \multicolumn{7}{|l|}{ Infant mortality } \\
\hline Born after Dec. 1991 & $\begin{array}{c}-12.637^{* *} \\
(6.213)\end{array}$ & $\begin{array}{c}-17.705^{* *} \\
(8.273)\end{array}$ & $\begin{array}{c}-13.626^{*} \\
(7.433)\end{array}$ & $\begin{array}{c}-12.386^{*} \\
(6.786)\end{array}$ & $\begin{array}{c}-12.183^{*} \\
(6.273)\end{array}$ & $\begin{array}{c}-13.698^{* *} \\
(5.916)\end{array}$ \\
\hline Bandwidth & 1799 & 1000 & 1250 & 1500 & 1750 & 2000 \\
\hline Observations & 637804 & 360502 & 448200 & 535007 & 621589 & 705141 \\
\hline Control group mean & 76.82 & 75.61 & 76.21 & 76.04 & 76.72 & 77.98 \\
\hline \multicolumn{7}{|l|}{ Child Mortality } \\
\hline Born after Dec. 1991 & $\begin{array}{c}-11.513^{*} \\
(6.809)\end{array}$ & $\begin{array}{l}-14.121 \\
(9.096)\end{array}$ & $\begin{array}{l}-11.91 \\
(8.163)\end{array}$ & $\begin{array}{c}-12.272^{*} \\
(7.458)\end{array}$ & $\begin{array}{c}-12.401^{*} \\
(6.92)\end{array}$ & $\begin{array}{c}-14.465^{* *} \\
(6.514)\end{array}$ \\
\hline Bandwidth & 1818 & 1000 & 1250 & 1500 & 1750 & 2000 \\
\hline Observations & 643921 & 360502 & 448200 & 535007 & 621589 & 705141 \\
\hline Control group mean & 91.37 & 89.36 & 89.77 & 89.81 & 91.18 & 92.54 \\
\hline \multicolumn{7}{|c|}{ Infant mortality excluding SIDS } \\
\hline Born after Dec. 1991 & $\begin{array}{l}-3.279 \\
(5.774)\end{array}$ & $\begin{array}{l}-10.591 \\
(7.055)\end{array}$ & $\begin{array}{l}-3.944 \\
(6.347)\end{array}$ & $\begin{array}{l}-3.673 \\
(5.834)\end{array}$ & $\begin{array}{l}-2.447 \\
(5.405)\end{array}$ & $\begin{array}{c}-2.262 \\
(5.097)\end{array}$ \\
\hline Bandwidth & 1533 & 1000 & 1250 & 1500 & 1750 & 2000 \\
\hline Observations & 545897 & 360502 & 448200 & 535007 & 621589 & 705141 \\
\hline Control group mean & 54.94 & 54.2 & 54.42 & 54.94 & 55.41 & 56.36 \\
\hline \multicolumn{7}{|c|}{ Child mortality excluding SIDS } \\
\hline Born after Dec. 1991 & $\begin{array}{l}-6.945 \\
(6.44)\end{array}$ & $\begin{array}{c}-13.026^{*} \\
(7.643)\end{array}$ & $\begin{array}{c}-5.37 \\
(6.861)\end{array}$ & $\begin{array}{c}-6.436 \\
(6.3)\end{array}$ & $\begin{array}{l}-5.216 \\
(5.851)\end{array}$ & $\begin{array}{l}-4.829 \\
(5.509)\end{array}$ \\
\hline Bandwidth & 1423 & 1000 & 1250 & 1500 & 1750 & 2000 \\
\hline Observations & 510634 & 360502 & 448200 & 535007 & 621589 & 705141 \\
\hline Control group mean & 63.17 & 62.72 & 62.51 & 63.26 & 64.14 & 65.14 \\
\hline
\end{tabular}

Notes: Table shows the regression discontinuity estimates for the effect of public health information campaign on infant and child mortality using a quadratic control function fit on each side of the discontinuity threshold. See Appendix Table $\mathrm{C} 1$ for the variable definitions. Each column indicates the bandwidth used to restrict the regression sample. Standard errors are clustered at the month-year cohort level and are shown in parentheses. Significance levels are indicated by ${ }^{* *}<0.01,{ }^{* *}<0.05$, and ${ }^{*}<0.1$. 
TABle C7: RD 2SLS efFects ON INFANT AND Child Mortality

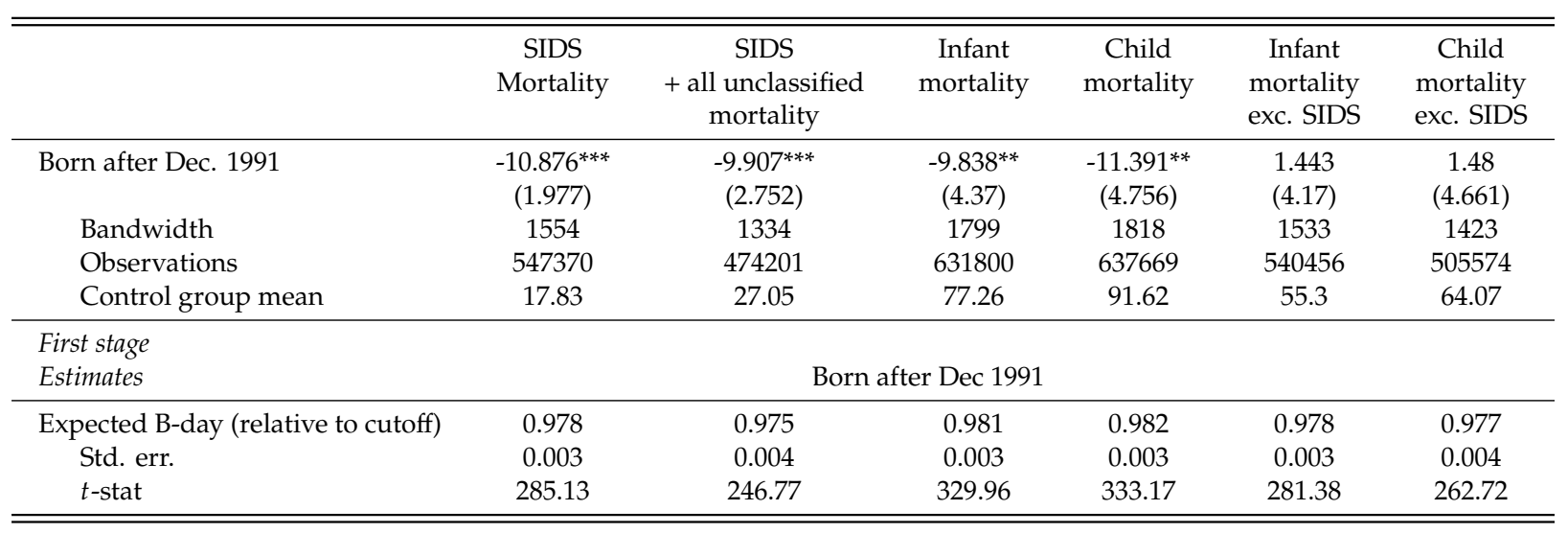

Notes: Table shows the regression discontinuity estimates for the effect of public health information campaign on infant and child mortality using a two-stage least squares estimator where the running variable is based on the expected birthday of the child, which is calculated by 280 days after the date of conception. The actual exposure to policy is instrumented by expected exposure, a dummy variable that indicates exposure based on the expected birthdate. See Appendix Table C1 for other variable definitions. Each column indicates the bandwidth used to restrict the regression sample. Standard errors are clustered at the birthday level and are shown in parentheses. Significance levels are indicated by ${ }^{* *}<0.01{ }^{* *}<0.05$, and ${ }^{*}<0.1$. 
TABLE C8: RD EFFECTS ON SMOKING

\begin{tabular}{lccccc}
\hline \hline & +1000 & +1250 & +1500 & +1750 & +2000 \\
\hline Smoking during 1 $1^{\text {st }}$ trimester & & & & & \\
\hline Born after Dec. 1991 & -0.008 & -0.008 & $-0.009^{*}$ & $-0.009^{*}$ & $-0.009^{*}$ \\
& $(0.005)$ & $(0.005)$ & $(0.005)$ & $(0.005)$ & $(0.005)$ \\
Bandwidth (left censored) & 1000 & 1250 & 1500 & 1750 & 2000 \\
Observations & 232954 & 278385 & 323389 & 368327 & 381654 \\
Control group mean & 0.34 & 0.34 & 0.34 & 0.34 & 0.34 \\
\hline \hline
\end{tabular}

Notes: Table shows the regression discontinuity estimates for the effect of public health information campaign on smoking after controlling for mother's age at birth, gender, month of birth, and birth order fixed-effects, dummy variables for low birthweight and preterm birth, mother's education category and immigrant status. See Appendix Table C1 for the variable definitions. Each column indicates the bandwidth used to restrict the regression sample. Standard errors are clustered at the birthday level, and are shown in parentheses. Significance levels are indicated by ${ }^{* *}<0.01,{ }^{* *}<0.05$, and ${ }^{*}<0.1$.

TABle C9: RD efFects all Unclassified Mortality

\begin{tabular}{lcccccc}
\hline \hline & MSE-optimal & \pm 1000 & \pm 1250 & \pm 1500 & \pm 1750 & \pm 2000 \\
\hline $\begin{array}{l}\text { All unclassified mortality } \\
\text { excluding SIDS }\end{array}$ & & & & & & \\
Born after Dec. 1991 & -0.24 & 0.288 & 0.678 & 0.507 & -0.243 & -0.012 \\
& $(1.365)$ & $(1.867)$ & $(1.664)$ & $(1.533)$ & $(1.447)$ & $(1.356)$ \\
Bandwidth & 1973 & 1000 & 1250 & 1500 & 1750 & 2000 \\
Observations & 695590 & 360502 & 448200 & 535007 & 621589 & 705141 \\
Control group mean & 9.17 & 8.75 & 8.93 & 8.83 & 9 & 9.24 \\
\hline \hline
\end{tabular}

Notes: Table shows the regression discontinuity estimates for the effect of public health information campaign on all unclassified mortality. See Appendix Table C1 for the variable definitions. Each column indicates the bandwidth used to restrict the regression sample. Standard errors are clustered at the birthday level, and are shown in parentheses. Significance levels are indicated by ${ }^{* * *}<0.01, * *<0.05$, and $*<0.1$. 
TABLE C10: CROSS-COUNTRY COMPARISON OF CHANGES IN INFANT MORTALITY AROUND THE SIDS CAMPAIGNS

\begin{tabular}{lccc}
\hline \hline Country & $\begin{array}{c}\text { Change in } \\
\text { infant mortality } \\
\text { (per 10K births) }\end{array}$ & $\begin{array}{c}\text { Control } \\
\text { group } \\
\text { mean }\end{array}$ & $\begin{array}{c}\text { Relative } \\
\text { change } \\
(\%)\end{array}$ \\
\hline Norway & -23.43 & 82.86 & -28.28 \\
Denmark & -19.14 & 78.86 & -24.28 \\
Sweden & -13.43 & 60.86 & -22.07 \\
Ireland & -16.86 & 83.43 & -20.21 \\
Belgium & -17.29 & 87.57 & -19.74 \\
France & -13.14 & 72.86 & -18.04 \\
Israel & -17.29 & 101.71 & -16.99 \\
United Kingdom & -14.71 & 89.86 & -16.38 \\
Australia & -10.57 & 89.86 & -11.76 \\
Japan & -5.14 & 44.14 & -11.65 \\
New Zealand & -10.86 & 105.29 & -10.31 \\
Italy & -4.29 & 54.71 & -7.83 \\
United States & -6.29 & 92.71 & -6.78 \\
Germany & -5 & 81.86 & -6.11 \\
Netherlands & -4.43 & 82.29 & -5.38 \\
Canada & -0.29 & 70 & -0.41 \\
Austria & 1.71 & 107.86 & 1.59 \\
Spain & 1.14 & 54.43 & 2.1 \\
\hline \hline
\end{tabular}

Notes: Table shows the changes in infant mortality between the preand post-SIDS campaign periods for the OECD countries. For all countries, the analysis sample is restricted to 7 years of aggregate data on infant mortality before the year of campaign and 7 years after the first year of the campaign. The regression controls for the pre- and post-campaign period linear trends separately and estimates a pseudo-RD coefficient for the drop in infant mortality over 10 thousand live births for first two years of the SIDS campaign. See the visualization of the trends and the changes in mortality for the same countries in Figure B8. 